\title{
Dopamine modulates visual threat processing in the superior colliculus via D2 receptors
}

4 Authors: Quentin Montardy ${ }^{1,6}$, Zheng Zhou ${ }^{1,4,6}$, Lei Li ${ }^{1,6}$, Qingning Yang ${ }^{1}$, Zhuogui Lei ${ }^{1,3}$, 5 Xiaolong Feng ${ }^{1}$, Shanping Chen ${ }^{1,2}$, Qianqian Shi ${ }^{1}$, Huiqi Zhang ${ }^{1}$, Shuran Chen ${ }^{1,2}$, Zhijian Zhang ${ }^{5}$, 6 Binghao Zhao ${ }^{1,2}$, Fuqiang $\mathrm{Xu}^{1,2}$, Zhonghua $\mathrm{Lu}^{1,2} \&$ Liping Wang ${ }^{1,2, *}$

\section{Affiliations:}

$8{ }^{1}$ Shenzhen Key Lab of Neuropsychiatric Modulation and Collaborative Innovation Center for Brain Science, Guangdong Provincial Key Laboratory of Brain Connectome and Behavior, CAS Center for Excellence in Brain Science and Intelligence Technology, the Brain Cognition and Brain Disease Institute (BCBDI), Shenzhen Institutes of Advanced Technology, Chinese Academy of Sciences, Shenzhen 518055, China; Shenzhen-Hong Kong Institute of Brain Science-Shenzhen Fundamental Research Institutions

${ }^{2}$ University of Chinese Academy of Sciences, Beijing 100049, China

${ }^{3}$ Department of Biomedical Sciences, City University of Hong Kong, Tat Chee Avenue, Kowloon, Hong Kong, SAR 999077, China

$18{ }^{4}$ McGovern Institute for Brain Research, Department of Brain and Cognitive Sciences, Massachusetts Institute of Technology, Cambridge, Massachusetts 02139, USA

${ }^{5}$ Center for Brain Science, Key Laboratory of Magnetic Resonance in Biological Systems and State Key Laboratory of Magnetic Resonance and Atomic and Molecular Physics, Wuhan Institute of Physics and Mathematics, CAS, Center for Excellence in Brain Science and Intelligence Technology, Chinese Academy of Sciences, Wuhan 430071, China

${ }^{6}$ These authors contributed equally to this work *Correspondence to:

26 Liping Wang, 1068 Xueyuan Avenue, Shenzhen University Town, Shenzhen, P.R. China; Email: lp.wang@siat.ac.cn.

\section{Abstract}

Dopamine (DA) system is intriguing in the aspect that distinct, typically opposing physiological functions are mediated by D1 dopamine receptors (Drd1) and D2 dopamine receptors (Drd2). Both Drd1+ and Drd2+ neurons were identified in superior colliculus (SC), a visuomotor integration center known for its role in defensive behaviors to visual threats. We hypothesized that Drd1+ and Drd2+ neurons in the SC may play a role in promoting instinctive defensive responses.

Optogenetic activation of Drd2+ neurons, but not Drd1+ neurons, in the SC triggered strong defensive behaviors. Chemogenetic inhibition of SC Drd2+ neurons decreased looming-induced defensive behavior, suggesting involvement of SC Drd2+ neurons in defensive responses. To 
further confirm this functional role of Drd2 receptors, pretreatment with the Drd2+ agonist quinpirole in the SC impaired looming-evoked defensive responses, suggesting an essential role of Drd2 receptors in the regulation of innate defensive behavior. Inputs and outputs of SC Drd2+ neurons were investigated using viral tracing: SC Drd2+ neurons mainly receive moderate inputs from the Locus Coeruleus (LC), whilst we did not find any incoming projections from other dopaminergic structures. Our results suggest a sophisticated regulatory role of DA and its receptor system in innate defensive behavior.

Keywords: Superior colliculus; Drd2 receptor; innate fear; looming; defensive responses.

\section{Introduction}

Defensive behaviors are essential for survival, and requires detection and optimal behavioral selection at the sensorimotor level. Dopamine (DA) is a neurotransmitter synthetized in a limited set of brain structures, including the zona incerta (ZI), the ventral tegmental area (VTA) and the locus coeruleus (LC) (Björklund and Dunnett, 2007). It is involved in the learning and prediction of aversive events (Cohen et al., 2012; de Jong et al., 2019; Matsumoto et al., 2016), in sensorimotor control (Barrios et al., 2020; Frau et al., 2016; Pérez-Fernández et al., 2017) and in action selection (Howard et al., 2017; Kardamakis et al., 2015). There is growing evidence which indicate DA's involvement in defensive behaviors (Barbano et al., 2020; Luo et al., 2018), notably that there is a high correlation between signal saliency and uncertainty when expecting an incoming aversive stimulation (Fiorillo, 2003; Jo et al., 2018). Extending this idea, dopamine is thought to have a dynamic effect on action and behavior selection at the earliest levels of sensory integration (Essig and Felsen, 2016; Hoyt et al., 2019; Kardamakis et al., 2015). The superior colliculus (SC), a subcortical structure receiving direct retinal afferents (Basso and May, 2017; Sparks, 1986), is known for its role in early sensorimotor integration (Ito and Feldheim, 2018). The SC is also thought to detect stereotypical salient visual information, such as snakes (Almeida et al., 2015), crawling in primates (Almeida et al., 2015; Isbell, 2011; Le et al., 2016; Maior et al., 2011), and collision or airborne predators in mice (Yilmaz and Meister, 2013), before relaying the information over a few synapses to core emotional centers such as the amygdala (Shang et al., 2015; Wei et al., 2015; Zhou et al., 2019). Thus, in recent years, several pathways originating from the SC have been identified, revealing an SC-Pulvinar-Amygdala pathway controlling defensive behaviors (Wei et al., 2015), and an SC-VTA-Amygdala pathway controlling flight behaviors (Zhou et al., 2019). Additionally, SC dysfunction in the early detection of visual threats is thought to negatively contribute to emotional and psychiatric disorders, in particular to Post Traumatic Stress Disorder (PTSD) (Lanius et al., 2017; Nicholson et al., 2017; Rabellino et al., 2016). 
1992), non-human primates (Ciliax et al., 2000) and humans (Hurd et al., 2001; Mengod et al., 1992). In mice, SC DA receptors are mainly Drd1 and Drd2 (Bolton et al., 2015), but their upstream targets remain elusive, and their function largely unknown. We hypothesized that SC neurons expressing dopaminergic receptors may be involved in defensive behaviors in response to visual threats.

\section{Results}

82 Optogenetic activation of Drd2+ neurons in the SC, but not D1R, induces immediate flight 83 behavior

84 To determine whether Drd1+ and Drd2+ SC neurons are involved in the control of defensive-like behaviors, we used an optogenetic strategy. First, we unilaterally injected the Cre-dependent adeno-associated virus AAV-DIO-ChR2-mCherry into the SC of Drd1-cre and Drd2-cre mice expressing Cre recombinase, selectively targeting SC neurons expressing dopamine receptors D1 or D2. Following virus injection, an optical fiber was placed above the SC (Fig. 1.A, up). Analysis of virus expression revealed that Drd2+ neurons were mostly localized in the intermediate SC layers (Fig. 1.B), whilst Drd1+ neurons were mainly found in the superficial SC layers (Fig. 1.C), confirming that these two categories of SC neurons are mainly segregated by different layers. To understand the function of each type in the context of defensive behaviors, mice were placed in an open field with a nest as a hiding place. They were allowed to explore the apparatus for 3 min (Fig. 1.A, down) during a pre-stimulation period in which both D2-cre and D1-cre animals showed typical exploratory behavior (Fig. 1.D, left). Optogenetic stimulation was then delivered (2.5 s, 20 $\mathrm{Hz}$ ), during which time D1-cre mice maintained normal activity yet D2-cre mice immediately fled to their nest before freezing inside for at least $30 \mathrm{~s}$ post-stimulation, (Fig. 1.D, supplementary video 1-2), an effect observed in every individual in the D2-cre group. Consist with this, only the D2::ChR2 group rapidly increased speed immediately following stimulation (Fig. 1.E). On average, when all groups were compared, only the D2::ChR2 mice had flight-to-nest behavior (latency: D1::ChR2: $22.97 \pm 6.8$ s; D2::ChR2: $0.59 \pm 0.12$ s; D2::mCherry $22.77 \pm 3.92$ $\mathrm{s} ; * * \mathrm{P}=0.0052, * * \mathrm{P}=0.0109$ ), shown by the latency to reach the nest after stimulation (Fig. 1.F). In addition, the average time spent in the nest after stimulation was similarly low for D1-cre and control D2-mCherry (D1::ChR2: $33.81 \pm 10.31 \%$; D2::mCherry $27.89 \pm 2.92 \%$; ****P<0.0001), and was significantly higher for D2:: ChR2 mice (D2::ChR2: $99.01 \pm 0.12 \%$; ****P<0.0001). These data suggest that Drd2+, but not Drd1+, SC neurons can induce defensive behaviors. Supporting this idea, SC Drd2+ neuronal projections (Sup. Fig. 1.A-B) encompass structures such as the lateral pulvinar, the ventral tegmental area, the parabigeminal nucleus, and the periaqueductal gray. In summary, these results indicate the Drd2+ neurons are sufficient to trigger

110 defensive behaviors. 
113 Repeated activation of SC Drd2+ neurons induces long-term memory and depression-like

\section{4 behavior}

115 To determine whether SC-Drd2 stimulation induces simple behavioral patterns or long-term 116 emotional states, we investigated whether aversive stimulation elicits long-term affective states.

117 To do this, we first used repeated activation of SC Drd2+ neurons to understand if would lead to 118 depression-like behavior. In detail, ChR2 and mCherry control groups received $2.5 \mathrm{~s}$ repeated 119 optogenetic stimulation for 3 consecutive trials $(20 \mathrm{~Hz}, 5 \mathrm{~ms}$ pulse duration, $5-8 \mathrm{~mW}, 1 \mathrm{~min}$ 120 interstimulus interval) over 3 consecutive days (Fig. 1.G). Five days after the previous session, a 121 tail-suspension test revealed that the ChR2 group remained immobile significantly longer than the

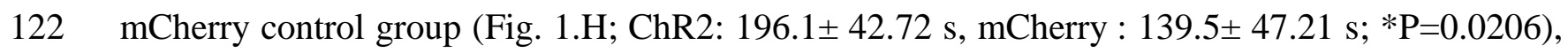
123 confirming that Drd2+ neurons can trigger long-term emotional states.

124 We next investigated whether SC Drd2 neuronal stimulation could lead to the formation of long125 term aversive memories. To answer this question, we placed mice in a contextualized box to 126 undergo classical Pavlovian conditioning (Fig. 1.I). Mice received an $80 \mathrm{~dB}$ tone over $30 \mathrm{~s}$ 127 conditioned stimulus (CS) terminated with a $2.5 \mathrm{~s} 20 \mathrm{~Hz}$ optogenetic stimulation of Drd2+ SC 128 neurons as an aversive unconditioned stimulus (US). Mice were placed in the same context without 129 tone delivery $24 \mathrm{~h}$ later or placed in a different context with tone delivery. During tone presentation 130 during the conditioning trial, freezing time for all animals was significantly higher in the ChR2 test 131 group than in the mCherry control group (ChR2 : 69.18\% $\pm 10.91 \%$, mCherry : 8.75\% $\pm 3.68 \%$; $132 * * * * \mathrm{P}<0.0001$ ), confirming that SC Drd2+ neurons activation promote defensive behaviors (Fig. 133 1.J). During context retrieval, the ChR2 group spent significantly longer freezing than the mCherry 134 controls (ChR2 : $22.55 \pm 2.87 \%$, mCherry : $9.81 \pm 1.67 \%$; ***P=0.0008) (Fig. 1.K, left). 135 Similarly, in a different context presentation of CS stimulation alone led to freezing time being 136 significantly higher in the ChR2 group than in the mCherry group (ChR2: 66.40\% $\pm 9.79 \%$, 137 mCherry : $26.22 \pm 4.06 \%$; *** $\mathrm{P}=0.0008$ ) (Fig. 1.K, right), overall indicating SC Drd2+ neuronal 138 stimulation is aversive and can be used as an effective US during memory formation.

139 Overall, these results suggest that Drd2+ neurons can not only trigger defensive responses, but are 140 also sufficient to promote formation of conditioned memories, and provoke long-term depression141 like behaviors.

144 Chemogenetic inhibition of D2R neurons impairs defensive behavior to looming stimuli

145 To question whether Drd2+ SC neurons are necessary to process visually-induced instinctive 146 defensive behaviors, we unilaterally injected AAV vectors containing the chemogenetic inhibitory 147 hM4Di receptors (AAV-DIO-HM4Di-mCherry) in the SC of Drd2-cre mice (Fig 2.A). Robust 148 expression of mCherry was observed in the intermediate layers of the SC (Fig. 2.B). Instinctive 149 defensive behaviors were elicited by placing mice in a box with a hiding nest, and by presenting 150 an overhead looming stimulation known to result in a rapid flight response (Yilmaz and Meister, 151 2013). One hour before stimulation, HM4Di-test and mCherry-control groups received an IP 152 injection of clozapine- $N$-oxide (CNO) (Fig. 2.A). During looming stimulation, flight latency was 
153 significantly higher in the HMDi-test group than in the control group (Fig 2.C; HM4Di : $3.54 \pm$ $1540.56 \mathrm{~s}$; mCherry : $2.25 \pm 0.22 \mathrm{~s}$; *P=0.034). There was a non-significant trend for mice in the 155 HM4Di-test group to spend less time in the nest than those in the control group, and the percentage 156 of flight following stimulation was similar between groups (Fig. 2.D). This indicates that inhibition of Drd2+ SC neurons disrupts defensive behaviors to visual threats.

Bilateral dopamine agonist quinpirole injection in the $\mathrm{SC}$ disrupts defensive responses to

\section{looming stimuli}

We next wanted to investigate the net effect of dopamine in the superior colliculus in the context of defensive behaviors, and in particular, whether dopamine could modulate Drd2+ SC neuronal activity following visual threat. To do so, we first used patch-clamp slice recordings to characterize the effect of dopamine on Drd2 neurons. By injecting an AAV-DIO-EYFP virus into the SC of Drd2-cre mice, neurons were determined and patched on slice based on fluorescence (Fig. 3.A). Quinpirole, a selective D2 receptor agonist, was then delivered to the cells resulting in suppression of Drd2+ SC neuronal activity, with firing rate drastically reduced compared to baseline levels (100\% VS. 14.54\%) (Fig. 3.B). Next, to understand the physiological role of dopamine on defensive behaviors to visual threats, we bilaterally injected quinpirole or saline solution into the $\mathrm{SC}$ of wild type mice, and then presented looming stimulation 30 minutes later (Fig. 3.C). Flight latency was significantly shorter (Quinpirole: $14.7 \pm 5.0 \mathrm{~s}$; Saline: $2.4 \pm 0.3 \mathrm{~s} ; * \mathrm{P}=0.026$ ) and the

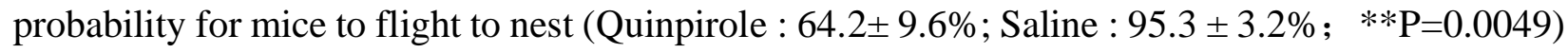
was significantly longer in the quinpirole group than in the saline control group, whilst time in the nest remained similar (Fig. 3.D). This confirms that dopamine modulates the SC activity and decreases defensive responses to aerial visual threat.

176 These blunted behavioral responses to visual threats suggest that SC D2 receptors are involved in triggering instinctive defensive behaviors to visual threats, and are necessary for the normal expression of the full repertoire of mouse behavior.

\section{The LC is the principal candidate sending dopaminergic projections to SC Drd2+ neurons} tracer cholera toxin B (CTB) into the SC (Sup. Fig. 2.A). CTB tracer was found in structures such as the primary visual cortex and the anterior cingulate cortex, both know to project to the SC (Baldwin et al., 2019; Zingg et al., 2017) (Sup. Fig. 2.B1-B2). CTB tracer was also found in the ventral tegmental area (VTA), the substantia nigra $(\mathrm{SN})$, the periaqueductal gray (PAG), the paraventricular nucleus of the hypothalamus (PVN), or the dorsal raphe nucleus (DRN), known to synthetize dopamine (Björklund and Dunnett, 2007) (Sup. Fig. 2.C1-C5, D1). Finally, we found strong CTB fluorescence retrograde tracer signal in neurons in the locus coeruleus (LC), as well as the zona incerta (ZI) (Sup. Fig. 2.D2-D3). Together, these data demonstrate that SC receives numerous projections from dopaminergic structures, confirming previous reports which used equivalent methods to show that ZI and LC to be a source of dopamine in SC (Bolton et al., 2015). 
193 But retrograde tracer injection of CTB is not specific to dopaminergic projections to SC Drd2 194 neurons. To determine the dopamine source of the SC neurons expressing dopamine receptor D2, 195 which possibly modulates defensive behaviors to visual threat, we mapped projections upstream 196 from Drd2+ SC neurons using a Cre-dependent monosynaptic retrograde tracing technique. Drd2 197 -Cre transgenic mice received AAV-CAG-DIO -TVA-GFP (AAV2/9) and AAV-CAG-DIO-RG 198 (AAV2/9) virus injections into SC. Three weeks after virus injection, the SC was infected with 199 RV-EvnA-DsRed (EnvA-pseudotyped, G-deleted and DsRed-expressing rabies virus) using the 200 same coordinates (Fig. 4.A). Whole brains were sectioned and stained with the fluorescent 201 dopamine synthesizing enzyme tyrosine hydroxylase (TH) to confirm upstream neurons were 202 capable of dopamine production. We found that the TVA-GFP and RV viruses were expressed in 203 the intermediate layers of SC (Fig. 4.B). Neurons co-expressing RV retrograde virus and TH 204 immunofluorescence were found in the locus coeruleus of every mouse (Fig. 4.C) with $78.34 \pm$ $2059.72 \%$ retrogradely labeled neuron being TH positive (Fig. 4.J), indicating that the LC sends 206 dopaminergic projections to Drd2 SC neurons. Neurons in other dopaminergic structures such as 207 the DRN, ZI, VTA, SN, PAG, or the arcuate nucleus also retrogradely expressed RV but did not 208 co-express TH fluorescence (Sup. Fig. 3.D-G We did not find dopaminergic inputs to SC Drd2+ 209 neurons using this method (Sup. Fig. 3.J). Together, these results suggest dopamine projections to 210 Drd2+ SC neurons could mainly come from LC.

\section{Conclusion and Discussion}

213 Conclusion:

We investigated the function of SC neurons expressing either Drd2 or Drd1dopaminergic receptors. Using optogenetic tools, we demonstrated that SC Drd2, but not Drd1, neuronal activation was able to induce strong defensive behaviors in the absence of threatening stimuli, and long-term effects such as fear memory and depression-like behaviors. Both chemogenetic inhibition using the HM4Di-CNO system, and physiological inhibition using the D2 receptor agonist quinpirole in vivo, impaired defensive behaviors to visual threats . Interestingly, CTB retrograde tracers revealed that $\mathrm{SC}$ receives projections from dopaminergic brain structures, results then extended by RV tracing showing that SC Drd2+ neurons receive transsynaptic dopaminergic projections from LC $\mathrm{TH}^{+}$neurons. These results suggest an essential and sophisticated role of dopamine in the SC, and behaviors

\section{Discussion:}

229 
232 Whilst dopamine D1 and D2 receptor expression in the mice superior colliculus has been reported, 233 their function was largely unknown. Here, we revealed that optogenetic activation of SC Drd2+ 234 neurons induced short and long-term defensive behaviors. These results are in line with previous 235 reports showing that direct SC stimulation can induce fear-like behavior in many species (Shang 236 et al., 2015; Wei et al., 2015; Zhou et al., 2019). Supporting this idea, we have shown that Drd2+ 237 neurons are mainly localized in the intermediate layers of the SC (Fig. 1.B), the same SC layers 238 that project to downstream structures involved in defensive and promoting flight behavior (Evans 239 et al., 2018; Zhou et al., 2019). Indeed, AAV tracing of SC Drd2 neurons demonstrated a projection 240 to structures known to receive SC inputs that control defensive behaviors (Zhou et al., 2019). Drd2+ 241 neurons, of which a major proportion are excitatory, enrich the intermediate layer of the SC, (May, 2006)-(Bolton et al., 2015). It is therefore possible that optogenetic activation of SC Drd2 neurons activates downstream nuclei involved in defensive behaviors, directly driving flight behaviors. In line with presented evidence showing that Drd 2 neuronal stimulation is able to trigger flight in the absence of visual threat, inhibition of these neurons impairs defensive behavior following visual threat. Indeed, we demonstrated that quinpirole injection into the SC weakens defensive responses, in particular by increasing flight latency and decreasing the flight probability. However, defensive behavior was not only diminished, indicating that disruption of SC Drd2 neurons alone is not sufficient to abolish defense. It is therefore likely that the SC Drd2 neurons do not encompass all of the SC neurons that project to emotion-related structures downstream.

In parallel, when exploring the function of Drd1 SC neurons, we found that this subpopulation is not involved in triggering defensive behaviors. Given that Drd1 and Drd2 receptors may have different on behavior (Liu et al., 2019; Smith and Kabelik, 2017; Tu et al., 2019; Verharen et al., 2019), it may have been expected that SC Drd1 neurons facilitate action to generate flight execution, but this not been observed here. Neurons with Drd1 and Drd2 receptors do not always participate in the same function (Smith and Kabelik, 2017). For example, D2, but not D1, neurons modulate auditory responses in the inferior colliculus (Hoyt et al., 2019). It is therefore reasonable to think that the function of Drd1 SC neurons may simply remain masked; indeed, dopamine at the SC level may have a broader scope of action than fear, such as the integration of visual signals among which looming-mimicking collisions are only a subset. Thus, to understand Drd1 SC role it would be necessary in the future to study the effects of dopamine on other non-emotional and more classical functions of the colliculus such as visuo-motor integration (Isa and Saito, 2001; Marino et al., 2008; Munoz et al., 1991) and attention selection (Ding et al., 2019; Evans et al., 2018; White et al., 2019).

Finally, we can suppose that a portion of the SC neurons expressing dopaminergic receptors act more locally at the microcircuitry level. Knowing that $37 \%$ of the Drd2 neurons are GABAergic (Bolton et al., 2015), it is likely that most form local inhibitory projections at the microcircuit level 
272 2010) and have even been associated with visual attention (Hafed et al., 2009). Knowing then, that

273 a proportion of these Drd2 neurons are GABAergic, and that we confirmed that DA inhibits Drd2

274 SC neurons, we can reasonably propose that DA can also act by removing local inhibition.

275 Weakened defensive responses could therefore be partly due to a release of lateral inhibition in the

276 SC (Kasai and Isa, 2016), disrupting the integration of the visual signal (or tuning it to optimize

277 detection of specific spatio-temporal frequencies) and indirectly leading to a reduction of defensive

278 responses. This raises the broader question of whether neuromodulation at the SC level disrupts

279 visual perception or impairs subsequent selection of action.

280 It is essential now to explore the effect of dopamine on local SC micro-circuitry to determine

281 whether it participates in visual signal integration, and which categories of behaviors it affects.

\section{On the circuitry aspect:}

Dopaminergic receptors at the SC level have been found in several species (Ciliax et al., 2000; Hurd et al., 2001; Mengod et al., 1992; Pérez-Fernández et al., 2014), suggesting that dopaminergic projections innervate the SC. In addition, it has been demonstrated using mice that dopaminergic projections from the ZI could target the SC (Bolton et al., 2015). In this study, the method used consisted of injecting latex microspheres, a retrograde tracer that has no particular affinity for neurons expressing dopaminergic receptors, into the SC. Thus, it demonstrated that ZI and LC could send DA projections to SC, but not that these projections target neurons expressing dopamine receptors. Here, we used an RV retrograde virus in conjunction with Drd2-cre mice, specifically mapping upstream pathways to SC neurons expressing DA receptors. We observed that several dopaminergic structures project towards Drd2 neurons, but we only found that the LC as sent dopaminergic projections to the SC (see Sup. Fig. 3.J). Since previous work revealed DA projections to SC, in particular from ZI, it will be necessary to carefully detail their connectivity patterns, and to understand their function.

Although we do not exclude the existence of other dopaminergic projections, we propose that the behavior. This hypothesis is in line with a previous report from our group demonstrating that the LC sends TH positive adrenergic projections to the SC ( $\mathrm{Li}$ et al., 2018). But these projections modulated defensive behavior following physiological stress by increasing flight probability, whilst here, we show a decrease of fear-like behaviors. To explain this discrepancy, it is necessary to note that Lie et al. used a NE antagonist, whilst we used DA agonist. Extending this idea, and knowing that a majority of LC neurons are NE positive (Amaral and Sinnamon, 1977; Robertson et al., 2013), it has been demonstrated that LC terminals can co-release dopamine and adrenaline/noradrenaline (Devoto et al., 2005a, 2005b). Dissociating the effect of DA from the one of $\mathrm{NE}$ in the context of LC-SC projections is important, but represents a real technical challenge to date. 
313 The LC-SC projections we revealed are only moderate and are unlikely to be responsible alone for 314 the behavioral phenomena reported in the present article. In addition, our CTB data are in line with 315 previous reports showing that the ZI sends dopaminergic projections to the SC. But these 316 projections do not target SC neurons expressing dopaminergic receptors, raising the question of 317 the mechanisms by which DA reaches dopaminergic receptors in the SC. Partly answering this 318 question, it is known and discussed that dopamine does not necessarily follow canonical neurotransmission mechanisms, and could follow a volume transmission mode of delivery (Fuxe et al., 2015; Liu et al., 2018; Sulzer et al., 2016). First, in other brain structures it has been shown that dopamine can be highly localized at the extra-synaptic rather than synaptic level (Devoto et al., 2003), whilst dopamine receptors are sometimes located far from their release sites (Caillé et al., 1996). In addition, recent studies revealed that the secretion of dopamine does not only take place at the synapse level, but could take place en-passant along the dopaminergic axons (Liu et al., 2018). This supports the hypothesis that diffusion and dilution are the main modes of action of the transmitter (for review: (Cragg and Rice, 2004; Rice et al., 2011; Rice and Cragg, 2008), which could explain how DA reaches dopaminergic receptors in SC without necessarily directly targeting specific receptors. In parallel, it is important to note that only a few sets of dopaminergic boutons can effectively release DA, as is the case in the striatum where only a minority of DA vesicles can release the transmitter (Pereira et al., 2016). This suggest that dopaminergic pathways to SC, whether projecting to DA receptors or not, are not necessarily active. Research on these particular DA transmission processes are still in their infancy, but this may explain in part why a proportion of the dopaminergic projections to SC do not directly synapse with neurons expressing D2 receptors. However, if such DA diffusion appears to be the prevalent mode of action in SC, it would make the role of DA in SC circuitry more challenging to elucidate. Understanding how, and in which context, dopamine is dynamically released in the SC is a key question for the near future.

It is of great importance for an animal to be able to predict the occurrence of a potential threat. A non-exclusive way to solve this problem is to optimize the detection of a threatening signal at the earliest stages of visual processing. We hypothesized DA could play such a role in the SC, and demonstrated Drd2 SC neurons were able to induce defensive responses even in the absence of visual threat, and were necessary for the normal expression of an optimal behavior. Our results suggest DA and its receptors regulate innate defensive behaviors in a sophisticated manner. Still, understanding in which condition DA is released in the SC is of high important, especially by which global and local mechanisms DA reaches its SC receptors, and understanding the dynamics involved. Understanding how defensive behaviors can be modulated from the earliest perceptive stage could help to find new therapeutic solutions to psychiatric pathologies, such as post-traumatic disorders. 


\section{EXPERIMENTAL MODEL AND SUBJECT DETAILS}

\section{Animals:}

All husbandry and experimental procedures in this study were approved by the Animal Care and Use Committees at the Shenzhen Institute of Advanced Technology (SIAT) or Wuhan Institute of Physics and Mathematics (WIPM), Chinese Academy of Sciences (CAS). Adult (6 to 8 weeks old) male C57BL/6J (Guangdong Medical Laboratory Animal Center, Guangzhou, China), Drd1-Cre (MMRRC_030989-UCD), and Drd2 -Cre (MMRRC_032108-UCD) mice were used in this study. Mice were housed at $22-25{ }^{\circ} \mathrm{C}$ on a circadian cycle of 12-hour light and 12-hour dark with adlibitum access to food and water.

\section{METHOD DETAILS}

\section{Viral vector preparation}

For optogenetic experiments, the plasmids for AAV2/9 viruses encoding EF1 $\alpha:$ DIO-hChR2 (H134R)-mCherry, EF1 $\alpha:$ : DIO-HM4Di- mCherry and EF1 $\alpha:$ DIO- mCherry were used. Viral vector titers were in the range of 3-6x10 12 genome copies per $\mathrm{ml}(\mathrm{gc}) / \mathrm{ml}$ and viruses were all packaged by BrainVTA Co., Ltd., Wuhan. For rabies tracing, the viral vectors AAV2/9-EF1 $\alpha$ : DIO-TVA-GFP, AAV2/9-EF1 $\alpha:$ DIO-RV-G, and EnvA-RV-dG-dsRed were used and were all packaged by BrainVTA Co., Ltd., Wuhan. For retrograde tracing, AAV and rabies viruses were purified and concentrated to titers at approximately $3 \times 10^{12} \mathrm{v} \cdot \mathrm{g} / \mathrm{ml}$ and $1 \times 10^{9} \mathrm{pfu} / \mathrm{ml}$, respectively.

\section{Virus injection}

Mice were placed in a stereotaxic apparatus (RWD, China) before being anesthetized with pentobarbital (i.p., $80 \mathrm{mg} / \mathrm{kg}$ ). Anesthesia was then maintained with isoflurane (1\%) during surgery and virus injections. Injections were conducted with a $10 \mu 1$ syringe (Neuros; Hamilton, Reno, USA), using a microsyringe pump (UMP3/Micro4, USA). Coordinates for virus injection of the $\mathrm{SC}$ in Drd2-Cre mice (total volume of $350 \mathrm{nl}$ ) were: bregma $-3.80 \mathrm{~mm}$, lateral $\pm 0.80 \mathrm{~mm}$ and dura $-1.80 \mathrm{~mm}$. SC in Drd1-Cre mice (total volume of $200 \mathrm{nl}$ ) coordinates were: AP $-3.40 \mathrm{~mm}, \mathrm{ML} \pm 0$. $50 \mathrm{~mm}$, and DV $-1.5 \mathrm{~mm}$. Viruses were delivered unilaterally for ChR2 and bilaterally for HM4Di.

\section{Trans-synaptic tracer labeling}

All animal procedures were performed in Biosafety level 2 (BSL2) animal facilities. To determine whether the inputs of Drdr2+ and Drd1+ neurons in the SC, Drd2-Cre mice and Drd1 were used for trans-mono-synaptic tracing based on the modified rabies virus. A mixture of AAV2/9-EF1 $\alpha:$ : DIO-RV-G and AAV2/9-EF1 $\alpha:$ DIO-TVA-GFP (1:1, total volume of 200-250 nl) was injected into the SC region. For virus injection into the SC in Drd2-Cre mice (total volume of $250 \mathrm{nl}$ ), the following coordinates were used: AP $-3.80 \mathrm{~mm}, \mathrm{ML} \pm 0.80 \mathrm{~mm}$ and DV $-1.80 \mathrm{~mm}$. Coordinates for SC injections in Drd1-Cre mice (total volume of $200 \mathrm{nl}$ ) were: AP -3.40 mm, ML $\pm 0.50 \mathrm{~mm}$, and DV $-1.5 \mathrm{~mm}$. Three weeks later, $200 \mathrm{nl}$ of EnvA-RV-dG-dsRed virus was injected into the same coordinates in these mice. Mice were sacrificed one week after RV injection. 


\section{Implantation of optical fiber(s) and cannulas}

A $200 \mu \mathrm{m}$ optic fiber (NA: 0.37; NEWDOON, Hangzhou) was unilaterally implanted into the $\mathrm{SC}$ in Drd2 mice (AP, -3.8 mm; ML, - $0.6 \mathrm{~mm}$; DV, - $1.4 \mathrm{~mm}$ ) and SC in Drd1 mice (AP, -3.40 mm; $\mathrm{ML},-0.5 \mathrm{~mm}$; DV, $-1.0 \mathrm{~mm})$. For pharmacological experiments, drug cannulas were bilaterally implanted into the SC (AP, $-3.8 \mathrm{~mm}$; ML, $\pm 0.6 \mathrm{~mm}$; DV , $-1.4 \mathrm{~mm}$ ). The mice were used for behavioral tests at least 1-2 weeks after surgery.

\section{Patch-clamp electrophysiology}

Coronal slices $(300 \mu \mathrm{m})$ containing the SC were prepared, using standard procedures, from 1416 week-old Drd2-Cre mice, which had received virus injections three weeks earlier. Recordings in SC Drd2+ cells were made on visually identified neurons expressing EYFP.

Brain slice were cut using a vibratome (Leica) into a chilled slicing solution (in mM: 1.3 (ACSF) (in mM: 10 Glucose, $2 \mathrm{CaCl}_{2}, 1.3 \mathrm{MgCl}_{2}, 125 \mathrm{NaCl}, 2.5 \mathrm{KCl}, 1.3 \mathrm{NaH}_{2} \mathrm{PO}_{4}, 25 \mathrm{NaHCO}_{3}$, $1.3 \mathrm{Na}$-Ascorbate, 0.6 Na-Pyruvate, $\mathrm{pH} 7.35$ ) and allowed to equilibrate to room temperature for $>30 \mathrm{~min}$. The osmolarity of all solutions was maintained at 280-300 mOsm.

411 For current clamp, pipettes were filled with a solution (in Mm: 105 Cs-gluconate, 10 phosphocreatine (Na), $0.07 \mathrm{CaCl}$, 4 EGTA, 10 HEPES, 4 Na-ATP, $1 \mathrm{Na}-\mathrm{GTP}$, and $3 \mathrm{MgCl} 2$ ).

413 To identify the spike dopaminergic nature, D2 agonist quinpirole $(10 \mu \mathrm{M})$ was added at the end 414 of recordings.

415 Pipettes with a resistance of 3-5 M $\Omega$ were formed by a micropipette puller (Sutter P-2000). We viewed neurons with an upright fixed-stage microscope (FN-S2N; Nikon., Japan) during wholelow-pass filtered at $2 \mathrm{kHz}$, digitized at $20 \mathrm{kHz}$ using Digidata 1440A, and recorded using pClamp 10 software (Molecular Devices).

\section{Histology, immunohistochemistry, and microscopy}

Mice were anesthetized with an overdose of chloral hydrate $(10 \% \mathrm{~W} / \mathrm{V}, 300 \mathrm{mg} / \mathrm{kg}$ body weight, i.p.) and were then transcardially perfused with PBS, followed by ice-cold $4 \%$ paraformaldehyde (PFA; Sigma) in PBS. Brains were extracted and submerged in $4 \%$ PFA at $4{ }^{\circ} \mathrm{C}$ overnight to postwere using a cryostat microtome (Lecia CM1950, Germany). Freely floating sections were incubated with PBS, containing blocking solution (0.3\% TritonX-100 and 10\% normal goat serum, NGS in PBS, $1 \mathrm{~h}$ at room temperature). Primary antibody (rabbit anti-TH, 1:500, Abcam) were overnight. The secondary antibody Alexa fluor 488 (1:200, Jackson) was used to incubated at room temperature for $1 \mathrm{~h}$. Slices were mounted and covered slipped with anti-fade reagent with DAPI 
For the rabies monsynaptic tracing, imagines were taken and then overlaid with The Mouse Brain in Stereotaxic Coordinates to locate the brain slices. Retrogradely identified positive neurons upstream of SC were manually counted by an individual experimenter blind to the experiment groups.

\section{Optogenetic manipulation}

Before optogenetic stimulation, animals were handled and habituated for $10-15$ min to the looming box with a nest shelter in corner one day before testing. During the test session, mice were put into the same looming box and allowed to freely explore the box for 3-5 min, then received 2.5 s of 473-nm blue laser (Aurora-220-473, NEWDOON, Hangzhou) with light power at the fiber tips $(20 \mathrm{~Hz}, 5 \mathrm{~ms}$ pulse duration, 5-8 mW). Light stimulation was unilaterally delivered to the SC Drd1+ and Drd2+ cells without looming stimulation in this experiment. Light was presented twice at approximately 3-min intervals via a manual trigger. We manually triggered stimulation when mice were at the far end of the open field, away from the nest position, within one body-length distance from the wall.

\section{Fear conditioning}

Fear conditioning was done over two sessions: a training session and a memory test. During the box. The Drd2-cre mice were allowed to freely explore the chamber for 3 mins before an 85-dB, secs light stimulations $(20 \mathrm{~Hz}, 5 \mathrm{~ms}$ pulse duration, 5-8 $\mathrm{mW}$ ) separated by 1-min intervals. Mice were kept in the training chamber for another $60 \mathrm{~s}$ before being moved outside. Each mouse received 5 repeated CS paired light stimulations.

During the memory test, mice performed consecutive tests: context test and tone test. 1) context test: mice were placed back into the altered chamber (modified by changing the white silver side walls to plastic walls decorated with black and white stripes, and changing the metal grid floor to a plastic sheet) for 5 mins to measure levels of freezing. 2) Tone test: an $80-\mathrm{dB}, 2-\mathrm{kHz}$ tone was presented for 1 min after the context test to measure freezing levels during the tone. $20 \%$ ethanol was used to clean the chamber to eliminate odors from other mice. All behavior were recorded and scored by the FreezeFrame fear conditioning system (Lafayette Instrument). Behavioral analysis was done blind to treatment group.

\section{Tail suspension test} $\mathrm{Hz}, 5 \mathrm{~ms}$ pulse duration, 5-8 $\mathrm{mW}$ ) in the SC with 1-min intervals (3 times repeated light suspension tests were performed 7 days after last light stimulation. 
camera (Sony, Shanghai, China) positioned in front of the box was used to record behavior.

\section{Looming test and Pharmacological antagonism}

A $40 \times 40 \times 30 \mathrm{~cm}$ closed Plexiglas box with a shelter nest in the corner was used for the overhead looming test. The looming box contained an LCD monitor on the ceiling to present a black disc expanding from a visual angle of $2^{\circ}$ to $20^{\circ}$ in 0.3 s, i.e., expanding speed of $60 \%$. Each looming stimulus included 15 repetitions of the expanding disc stimulus with a $0.066 \mathrm{~s}$ interval between each. Each looming stimulus lasted $5.5 \mathrm{~s}$.

An HD digital camera (Sony, Shanghai, China) was used to record behavior. The behavioral test included two sessions, a pre-test and a test session. During the pre-test session, mice were handled and habituated for 10-15 min to the looming box one day before testing. During the test session, $200 \mathrm{nl}$ saline (control) or D2 receptor agonists per hemisphere (Quinpirole, $0.25 \mu \mathrm{g} /$ /side) was bilaterally infused into the SC (AP, $-3.8 \mathrm{~mm}$; ML, $\pm 0.6 \mathrm{~mm}$; DV, $-1.85 \mathrm{~mm}$ ) $30 \mathrm{~min}$ before a looming test. Then, mice were put in the box and allowed to freely explore the box for 3-5 min. For pharmacological experiments plus looming, mice received 3 trials of looming stimulus but only defensive behavior to the first stimulus was analyzed; no observable adaptation was observed in any of the experiments.

\section{Behavioral analysis}

495

Behavioral data were analyzed with Anymaze software. Individual time courses were plotted where $\mathrm{T}=0 \mathrm{~ms}$ as the time of stimulation. There three measures were obtained as indices of lightevoked or looming-evoked defensive behavior. (1) latency to return nest: the time from photostimulation or looming stimulus presentation to time when the mouse escaped/entered the nest; (2) time spent in nest (\% of $1 \mathrm{~min}$ bin): time spent in the nest following looming stimulus or photostimulation; (3) percentage of flight ( $\%$ of 3 repeated trial of looming stimulus). the probability of flight to nest after looming stimulus in 3 repeated photostimulation.

Flight is defined as episodes where speed increases 4 times than the average speed in cases where the final position is in the nest.

For all mice in this study, virus expression and fiber placements or cannula were confirmed by histological staining after our data were collected. Virus expression, behavioral tests and behavior analyses were performed by different experimenters. Decisions to discarded data on any given day was done blind to the behavioral groupings.

\section{QUANTIFICATION AND STATISTICAL ANALYSIS}

515

All statistics were performed in Graph Pad Prism (GraphPad Software, Inc.), unless otherwise indicated. Paired student tests, unpaired student tests, and one-way ANOVAs were used and Bonferroni post hoc comparisons were conducted to detect significant main effects or interactions. In all statistical measures a $\mathrm{P}$ value $<0.05$ was considered statistically significant. Post hoc significance values were set as $* \mathrm{P}<0.05$, $* * \mathrm{P}<0.01$, ${ }^{*} * \mathrm{P}<0.001$ and $* * * * \mathrm{P}<0.0001$; all statistical tests used are indicated in the figure legends. 


\section{Acknowledgements}

518 This work was supported by National Natural Science Foundation of China (NSFC) 31630031 519 (L.W .), NSFC 31930047(L.W .), NSFC 81425010 (L.W .), NSFC31971072 (L.L.); International 520 Partnership Program of Chinese Academy of Sciences 172644KYS820170004 (L.W.); Helmholtz521 CAS Joint Research Grant GJHZ1508 (L.W.); the Strategic Priority Research Program of Chinese 522 Academy of Science, XDB32030200; Guangdong Provincial Key Laboratory of Brain 523 Connectome and Behavior 2017B030301017 (L.W.); JCYJ20170413164535041(L.W.), 524 JCYJ20150401150223647 (Z.Z.); Shenzhen Municipal Funding GJHZ20160229200136090 525 (L.W.); Shenzhen Discipline Construction Project for Neurobiology DRCSM [2016]1379 526 (L.W.);Science and Technology Planning Project of Guangdong Province 2018B030331001(L.W.); CAS President's International Fellowship 2020FYB0005 (Q.M.); Guangdong Province International Scientific and Technological Cooperation 2019A050508008 (M.Q.).

\section{Author contributions}

M.Q., Z.Z., and L.L. contributed equally to this work. M.Q., Z.Z., L.L. and L.W. designed and initiated the project. Z.Z. performed virus injections, fiber and cannula implantation. M.Q., Z.Z and L.L. setup the behavior protocol. Z.Z., X.F., Q.S., Z.L. (Zhuogui Lei), M.Q and L.L. performed behavior experiments. Z.Z., M.Q. and L.L. processed and analyzed behavior data. Z.Z. performed quantitative analyzes of the tracing data. S.C. performed the patch clamp recording. Z.L. (Zhonghua $\mathrm{Lu}$ ) provided the viral vectors. Q.M., Z.Z., L.L. and L.W. interpreted the results. M.Q.,

\section{Supplementary Figure Legends}

542 Fig. 1: Optostimulation of SC D2+ neurons induced strong defensive behaviors and fear memory

543 Fig. 2: Chemogenetic inhibition of SC D2+ neurons decreased the looming-induced defensive 544 behavior of the mice

545 Fig. 3: Drd2 agonist suppressed SC D2+ neurons firing at brain slice recording intra-SC, and SC 546 infusion dampened the looming-induced defensive behaviors in vivo.

547 Fig. 4: SC D2+ neurons receive direct monosynaptic TH-positive inputs from LC.

548 Sup. Fig. 1: The outputs of SCD2+ neuron

549 Sup. Fig. 2: CTB-based retrograde tracing identified the input of SC neurons

550 Sup. Fig. 3: Rabies virus-based viral tracing identified the input of SC D2+ neurons 

neurons $(\mathrm{C})$, and the position of the fiber track (blue, DAPI; red, ChR2-mCherry; scale bars, $500 \mu \mathrm{m}$ and $50 \mu \mathrm{m}$, respectively; solid line, fiber track).

(D) Representative track plots of the $\mathrm{SC}^{\mathrm{D} 2+}$ activated (up) and $\mathrm{SC}^{\mathrm{D} 1+}$ (bottom) activated mice in open field with a nest demonstrating flight-to-nest defensive behavior of $\mathrm{SC}^{\mathrm{D} 2+}$ activated mouse.

(E) Representative speed profiles illustrate shorter flight latency after SC-D2+ activation in the ChR2mCherry group than in the mCherry control group.

(F) Following photostimulation of SC ${ }^{\mathrm{D} 2+}$ neurons, the $\mathrm{D} 2::$ ChR2 group had lower flight

latencies and higher time in the nest compared with controls $\left(\mathrm{n}_{\mathrm{D} 2-\mathrm{mCherry}}=11\right.$ mice; $\mathrm{n}_{\mathrm{D} 1-\mathrm{ChR} 2}=7$ mice, $\mathrm{n}_{\mathrm{D} 2}$ $\mathrm{ChR}_{2}=7$ mice; $* * P_{\text {latency }}=0.0032, F_{2,22 \text { latency }}=7.553, * * * * P_{\text {time }}<0.0001, F_{2,22}$ time $=48.9$; Bonferroni post hoc test, for latency: D2-ChR2 VS. D2-mCherry, $* * P P_{\text {latency }}=0.0052$; D1-ChR2 VS. D2-ChR2, $* * P$ latency $=$ 0.0109; for time in nest: D2-ChR2 VS. D2-mCherry, ****P time $<0.0001$; D1-ChR2 VS. D2-ChR2, $* * * * P_{\text {time }}<0.0001$; one-way ANOVA).

For all graphs, data were presented as mean \pm SEM.

(G) Experimental procedure for the repeated activation of SC ${ }^{\mathrm{D} 2+}$ neurons caused depression-like behavior as indexed by elevated freezing.

572 (H) Repeated activation of $\mathrm{SC}^{\mathrm{D} 2+}$ neurons induced significant higher immobility time in the ChR2 group than in the control group ( $\mathrm{n}_{\text {mCherry }}=11$ mice, $\mathrm{n}_{\mathrm{ChR} 2}=7$ mice, $t_{16}=2.569, * P=0.0206$; Unpaired student test).

(I) Schematic of the conditioned paring of activation of SC ${ }^{\mathrm{D} 2+}$ neuronal activation and the tone.

(J) Optogenetic stimulation SC ${ }^{\mathrm{D} 2+}$ neurons increased freezing levels during conditioning $\left(\mathrm{n}_{\mathrm{D} 2-\mathrm{mCherry}}=11\right.$ mice; $\mathrm{n}_{\mathrm{D} 2-\mathrm{ChR} 2}=7$ mice; Group x trial effect interaction, $F_{4,19}=11.77$, $* * * * P<0.0001$, two-way ANOVA bonferroni post hoc test, $* * * * P<0.0001)$.

(K) Testing day: compared with D2-mCherry group, the D2-ChR2 group had a significantly higher percentage of freezing time in context (K-left) and tone (K-right) memory retrieval $\left(\mathrm{n}_{\text {mCherry }}=11\right.$ mice, $\mathrm{n}$ $\mathrm{ChR}_{2}=7$ mice, for context, $t_{16}=4.13$, ***P=0.0008; for tone, $t_{16}=4.132$, *** $P=0.0018$; unpaired student test).

Figure 2. Chemogenetic inhibition of $\mathrm{SC}^{\mathrm{D} 2+}$ neurons decreased looming-induced defensive behavior.

(A) Chemogenetic strategy showing bilateral SC inhibition and experimental timeline.

(B) Representative IHC showing selective targeting of hM4Di-mCherry to $\mathrm{SC}^{\mathrm{D} 2+}$ neurons (blue, DAPI; red, hM4Di-mCherry; scale bars, $200 \mu \mathrm{m}$ and $20 \mu \mathrm{m}$, respectively).

(C) After CNO administration, the flight latency in the hM4Di group was higher than the mCherry controls ( $\mathrm{n}_{\text {mCherry }}=10$ mice, $\mathrm{n}_{\text {HM } 4 \mathrm{Di}}=8$ mice, for latency, $t_{16}=2.326, * P=0.0335$; for time in nest, $t$ ${ }_{16}=1.769, P=0.0959$; for percentage of flight, $t_{16}=0.1582, P=0.8762$; unpaired student $\mathrm{t}$ test).

For all graphs, data are presented as mean \pm SEM.

Figure 3. Drd2 agonist suppressed $\mathrm{SC}^{\mathrm{D} 2+}$ neurons firing at brain slice recording intra-SC, and SC infusion dampened the looming-induced defensive behaviors in vivo.

(A) Schematic showing in vitro patch-clamp slice recording of single-unit SC-D2+ neuronal activity following Drd2 agonist injection into the SC. AAV- DIO-EYFP injections in D2-cre mice were used to visualize D2-positive neurons.

(B) Right, representative example of firing rate showing that the activity of SC-D2+ neurons was suppressed after infusion with Drd2 agonist; left, quantification of the firing rate of SC-D2+ neurons ( $\mathrm{n}=3$ cells from 3 mice, data presented as mean $\pm \mathrm{SEM}, * * \mathrm{P}=0.0033, \mathrm{t} 2=17.30$, Paired student $\mathrm{t}$ test)

601

602

603

(C) Bilateral Drd2 agonist strategy showing bilateral SC agonist infusion and experimental timeline.

(D) The looming-induced flight-to-nest behavior was reduced by intra-SC infusion of Quinpirole (dopamine receptor 2 agonist), resulting in a recovery of flight latency and lower percentage of flight- 
604

605

606

607

608

609

610

611

612

613

614

615

616

617

618

619

620

621

622

623

624

625

626

627

628

629

630

631

632

633

634

635

636

637

638

639

640

641

642

643

644

645

646 to-nest ( $\mathrm{n}_{\text {saline }}=14$ mice, $\mathrm{n}_{\text {Quinpirole }}=14$ mice, for latency, $t_{27}=2.353, * P=0.0262$; for time in nest, $t$ ${ }_{27}=2.372, P=0.909$; for percentage of flight, $t_{27}=3.007$, ** $P=0.0049$; Unpaired student $\mathrm{t}$ test).

For all graphs, data are presented as mean \pm SEM.

Figure 4. $\mathrm{SC}^{\mathrm{D} 2+}$ neurons receive direct monosynaptic TH-positive inputs from LC.

(A) Schematic of the rabies virus-based cell-type-specific monosynaptic tracing protocol.

(B) Representative images denoting the starter cells in the SC of D2-Cre mice (Red, rabies-dsRed; green, TVA; blue, DAPI; scale bar, $250 \mu \mathrm{m}$ and $25 \mu \mathrm{m}$, respectively).

(C-F) SC-D2 RV retrograde labelled upstream brain regions and co-labelling with TH. Retrograde labelled cells (Red) in the (C) Locus coeruleus (LC), (D) Dorsal raphe (DRN), (E) Substantia nigra, compact part(SNc), Substantia nigra, reticular part(SNr), (F) Ventral tegmental area (VTA), (G) Zona incerta (ZI), (H)Ventromedial hypothalamic nucleus(VMH), Arcuate hypothalamic nucleus (Arc) and (I) Periaqueductal gray(PAG) with inputs to SC-D2+ neurons, (Red, rabies-dsRed; green, TH; blue, DAPI, scale bar, $250 \mu \mathrm{m}$ and $20 \mu \mathrm{m}$ respectively).

(J) Quantification of the percentage of rabies-dsRed labeled neurons that overlap with TH in regions upstream of SC-D2+ cells. ( $\mathrm{n}=5$ mice, $F_{6,28}=65.01$, $* * * P<0.0001$, data presented as mean $\pm \mathrm{SEM}$; one-way ANOVA).

\section{Supplementary Figure 1. The outputs of $\mathrm{SC}^{\mathrm{D} 2+}$ neuron}

(A) Anterograde tracing of $\mathrm{SC}^{\mathrm{D} 2+}$ neurons show fibers in the Parabigeminal nucleus (PBGN), Pontine nuclei (Pn), Periaqueductal gray (PAG), Ventral tegmental area (VTA) and lateral posterior nucleus of the thalamus (LP), and with images of the terminal fibers (scale bars, $500 \mu \mathrm{m}$ ).

(B) Schematic image of the outputs of the D2-Cre neurons from SC.

\section{Supplementary Figure 2. CTB-based retrograde tracing identified the input of SC neurons.}

(A) CTB-594 retrograde tracer was injected into SC.

(B-D) CTB-594 labeled neurons in regions of primary visual cortex, V1(B1); ACC (B2); VTA(B3); SNc

(C1); SNr (C1); DRN (C2); PVN (C3); PAG (D1); VMH (D2); ZI (D2) and LC (D3); (Red, CTB; blue,

DAPI, scale bar, $1000 \mu \mathrm{m}, 500 \mu \mathrm{m}$ and $20 \mu \mathrm{m}$, repsectively).

\section{Supplementary Figure 3. Rabies virus-based viral tracing identified the input of} $\mathrm{SC}^{\mathrm{D} 2+}$ neurons.

(A-E) Rabies-dsRed labeled neurons in regions of LC, DRN, VTA, PAG, anterior cingulate cortex (ACC), VMH, Arc, SNr, SNc and Primary visual cortex (V1); (Red, rabies-dsRed; blue, DAPI, scale bar, $200 \mu \mathrm{m}$ and $20 \mu \mathrm{m}$ ).

(F)Quantification of the number of rabies-dsRed labeled neurons in regions upstream of the SC ( $\mathrm{n}=18-48$ slices from 5 mice, data presented as mean \pm SEM) 


\section{References}

Almeida, I., Soares, S.C., Castelo-Branco, M., 2015. The Distinct Role of the Amygdala, Superior Colliculus and Pulvinar in Processing of Central and Peripheral Snakes. PLoS ONE 10, e0129949. https://doi.org/10.1371/journal.pone.0129949

Amaral, D., Sinnamon, H., 1977. The locus coeruleus: neurobiology of a central noradrenergic nucleus. Progress in Neurobiology 9, 147-196. https://doi.org/10.1016/0301-0082(77)90016-8

Baldwin, M.K.L., Young, N.A., Matrov, D., Kaas, J.H., 2019. Cortical projections to the superior colliculus in grey squirrels (Sciurus carolinensis ). Eur J Neurosci 49, 1008-1023. https://doi.org/10.1111/ejn.13867

Barbano, M.F., Wang, H.-L., Zhang, S., Miranda-Barrientos, J., Estrin, D.J., FigueroaGonzález, A., Liu, B., Barker, D.J., Morales, M., 2020. VTA Glutamatergic Neurons Mediate Innate Defensive Behaviors. Neuron 107, 368-382.e8. https://doi.org/10.1016/j.neuron.2020.04.024

Barrios, J.P., Wang, W.-C., England, R., Reifenberg, E., Douglass, A.D., 2020. Hypothalamic Dopamine Neurons Control Sensorimotor Behavior by Modulating Brainstem Premotor Nuclei in Zebrafish. Current Biology S0960982220313336. https://doi.org/10.1016/j.cub.2020.09.002

Basso, M.A., May, P.J., 2017. Circuits for Action and Cognition: A View from the Superior Colliculus. Annu Rev Vis Sci 3, 197-226. https://doi.org/10.1146/annurev-vision-102016-061234

Björklund, A., Dunnett, S.B., 2007. Dopamine neuron systems in the brain: an update. Trends in Neurosciences 30, 194-202. https://doi.org/10.1016/j.tins.2007.03.006

Bolton, A.D., Murata, Y., Kirchner, R., Kim, S.-Y., Young, A., Dang, T., Yanagawa, Y., Constantine-Paton, M., 2015. A Diencephalic Dopamine Source Provides Input to the Superior Colliculus, where D1 and D2 Receptors Segregate to Distinct Functional Zones. Cell Reports 13, 1003-1015. https://doi.org/10.1016/j.celrep.2015.09.046

Caillé, I., Dumartin, B., Bloch, B., 1996. Ultrastructural localization of D1 dopamine receptor immunoreactivity in rat striatonigral neurons and its relation with dopaminergic innervation. Brain Research 730, 17-31. https://doi.org/10.1016/0006-8993(96)00424-6 
682 Ciliax, B.J., Nash, N., Heilman, C., Sunahara, R., Hartney, A., Tiberi, M., Rye, D.B.,

683

684

685

686

687

688

689

690

691

692

693

694

695

696

697

698

699

700

701

702

703

704

705

706

707

708

709

710

711

712

713

714

715

716

717

Caron, M.G., Niznik, H.B., Levey, A.I., 2000. Dopamine D(5) receptor immunolocalization in rat and monkey brain. Synapse 37, 125-145. https://doi.org/10.1002/1098-2396(200008)37:2<125::AID-SYN7>3.0.CO;27

Cohen, J.Y., Haesler, S., Vong, L., Lowell, B.B., Uchida, N., 2012. Neuron-type-specific signals for reward and punishment in the ventral tegmental area. Nature 482, 85-88. https://doi.org/10.1038/nature10754

Cragg, S.J., Rice, M.E., 2004. DAncing past the DAT at a DA synapse. Trends Neurosci 27, 270-277. https://doi.org/10.1016/j.tins.2004.03.011

de Jong, J.W., Afjei, S.A., Pollak Dorocic, I., Peck, J.R., Liu, C., Kim, C.K., Tian, L., Deisseroth, K., Lammel, S., 2019. A Neural Circuit Mechanism for Encoding Aversive Stimuli in the Mesolimbic Dopamine System. Neuron 101, 133151.e7. https://doi.org/10.1016/j.neuron.2018.11.005

Devoto, P., Flore, G., Longu, G., Pira, L., Gessa, G.L., 2003. Origin of extracellular dopamine from dopamine and noradrenaline neurons in the medial prefrontal and occipital cortex. Synapse 50, 200-205. https://doi.org/10.1002/syn.10264

Devoto, P., Flore, G., Saba, P., Fa, M., Gessa, G.L., 2005a. Stimulation of the locus coeruleus elicits noradrenaline and dopamine release in the medial prefrontal and parietal cortex. J Neurochem 92, 368-374. https://doi.org/10.1111/j.1471-4159.2004.02866.x

Devoto, P., Flore, G., Saba, P., Fà, M., Gessa, G.L., 2005b. Co-release of noradrenaline and dopamine in the cerebral cortex elicited by single train and repeated train stimulation of the locus coeruleus. BMC Neurosci 6, 31. https://doi.org/10.1186/1471-2202-6-31

Ding, Y., Xu, N., Gao, Y., Wu, Z., Li, L., 2019. The role of the deeper layers of the superior colliculus in attentional modulations of prepulse inhibition. Behavioural Brain Research 364, 106-113. https://doi.org/10.1016/j.bbr.2019.01.052

Essig, J., Felsen, G., 2016. Warning! Dopaminergic Modulation of the Superior Colliculus. Trends in Neurosciences 39, 2-4. https://doi.org/10.1016/j.tins.2015.12.002

Evans, D.A., Stempel, A.V., Vale, R., Ruehle, S., Lefler, Y., Branco, T., 2018. A synaptic threshold mechanism for computing escape decisions. Nature 558, 590-594. https://doi.org/10.1038/s41586-018-0244-6 
718 Fiorillo, C.D., 2003. Discrete Coding of Reward Probability and Uncertainty by https://doi.org/10.1126/science.1077349

Frau, R., Mosher, L.J., Bini, V., Pillolla, G., Pes, R., Saba, P., Fanni, S., Devoto, P., Bortolato, M., 2016. The neurosteroidogenic enzyme $5 \alpha$-reductase modulates the role of D1 dopamine receptors in rat sensorimotor gating. Psychoneuroendocrinology 63, 59-67. https://doi.org/10.1016/j.psyneuen.2015.09.014

Fuxe, K., Agnati, L.F., Marcoli, M., Borroto-Escuela, D.O., 2015. Volume Transmission in Central Dopamine and Noradrenaline Neurons and Its Astroglial Targets. Neurochem Res 40, 2600-2614. https://doi.org/10.1007/s11064-015-1574-5

Hafed, Z.M., Goffart, L., Krauzlis, R.J., 2009. A Neural Mechanism for Microsaccade Generation in the Primate Superior Colliculus. Science 323, 940-943. https://doi.org/10.1126/science.1166112

Howard, C.D., Li, H., Geddes, C.E., Jin, X., 2017. Dynamic Nigrostriatal Dopamine Biases Action Selection. Neuron 93, 1436-1450.e8. https://doi.org/10.1016/j.neuron.2017.02.029

Hoyt, J.M., Perkel, D.J., Portfors, C.V., 2019. Dopamine Acts via D2-Like Receptors to Modulate Auditory Responses in the Inferior Colliculus. eNeuro 6, ENEURO.0350-19.2019. https://doi.org/10.1523/ENEURO.0350-19.2019

Hurd, Y.L., Suzuki, M., Sedvall, G.C., 2001. D1 and D2 dopamine receptor mRNA expression in whole hemisphere sections of the human brain. Journal of Chemical Neuroanatomy 22, 127-137. https://doi.org/10.1016/S08910618(01)00122-3

Isa, T., Saito, Y., 2001. The direct visuo-motor pathway in mammalian superior colliculus; novel perspective on the interlaminar connection. Neuroscience Research 41, 107-113. https://doi.org/10.1016/S0168-0102(01)00278-4

Isbell, L.A., 2011. The fruit, the tree, and the serpent: why we see so well. Harvard University Press, Cambridge, Mass.

Ito, S., Feldheim, D.A., 2018. The Mouse Superior Colliculus: An Emerging Model for Studying Circuit Formation and Function. Front. Neural Circuits 12, 10. https://doi.org/10.3389/fncir.2018.00010

Jo, Y.S., Heymann, G., Zweifel, L.S., 2018. Dopamine Neurons Reflect the Uncertainty in Fear Generalization. Neuron 100, 916-925.e3. https://doi.org/10.1016/j.neuron.2018.09.028 
Kardamakis, A.A., Saitoh, K., Grillner, S., 2015. Tectal microcircuit generating visual selection commands on gaze-controlling neurons. Proc Natl Acad Sci USA 112, E1956-E1965. https://doi.org/10.1073/pnas.1504866112

Kasai, M., Isa, T., 2016. Imaging population dynamics of surround suppression in the superior colliculus. Eur J Neurosci 44, 2543-2556. https://doi.org/10.1111/ejn.13371

Lanius, R.A., Rabellino, D., Boyd, J.E., Harricharan, S., Frewen, P.A., McKinnon, M.C., 2017. The innate alarm system in PTSD: conscious and subconscious processing of threat. Current Opinion in Psychology 14, 109-115. https://doi.org/10.1016/j.copsyc.2016.11.006

Le, Q.V., Isbell, L.A., Matsumoto, J., Le, V.Q., Nishimaru, H., Hori, E., Maior, R.S., Tomaz, C., Ono, T., Nishijo, H., 2016. Snakes elicit earlier, and monkey faces, later, gamma oscillations in macaque pulvinar neurons. Sci Rep 6, 20595. https://doi.org/10.1038/srep20595

Li, Lei, Feng, X., Zhou, Z., Zhang, H., Shi, Q., Lei, Z., Shen, P., Yang, Q., Zhao, B., Chen, S., Li, Lin, Zhang, Y., Wen, P., Lu, Z., Li, X., Xu, F., Wang, L., 2018. Stress Accelerates Defensive Responses to Looming in Mice and Involves a Locus Coeruleus-Superior Colliculus Projection. Current Biology 28, 859-871.e5. https://doi.org/10.1016/j.cub.2018.02.005

Liu, C., Kershberg, L., Wang, J., Schneeberger, S., Kaeser, P.S., 2018. Dopamine Secretion Is Mediated by Sparse Active Zone-like Release Sites. Cell 172, 706718.e15. https://doi.org/10.1016/j.cell.2018.01.008

Liu, S., Tang, Y., Shu, H., Tatum, D., Bai, Q., Crawford, J., Xing, Y., Lobo, M.K., Bellinger, L., Kramer, P., Tao, F., 2019. Dopamine receptor D2, but not D1, mediates descending dopaminergic pathway-produced analgesic effect in a trigeminal neuropathic pain mouse model: PAIN 160, 334-344. https://doi.org/10.1097/j.pain.0000000000001414

Luo, R., Uematsu, A., Weitemier, A., Aquili, L., Koivumaa, J., McHugh, T.J., Johansen, J.P., 2018. A dopaminergic switch for fear to safety transitions. Nat Commun 9, 2483. https://doi.org/10.1038/s41467-018-04784-7

Maior, R.S., Hori, E., Barros, M., Teixeira, D.S., Tavares, M.C.H., Ono, T., Nishijo, H., Tomaz, C., 2011. Superior colliculus lesions impair threat responsiveness in infant capuchin monkeys. Neuroscience Letters 504, 257-260. https://doi.org/10.1016/j.neulet.2011.09.042

Marino, R.A., Rodgers, C.K., Levy, R., Munoz, D.P., 2008. Spatial Relationships of Visuomotor Transformations in the Superior Colliculus Map. Journal of Neurophysiology 100, 2564-2576. https://doi.org/10.1152/jn.90688.2008 
Matsumoto, H., Tian, J., Uchida, N., Watabe-Uchida, M., 2016. Midbrain dopamine neurons signal aversion in a reward-context-dependent manner. eLife 5, e17328. https://doi.org/10.7554/eLife.17328

May, P.J., 2006. The mammalian superior colliculus: laminar structure and connections, in: Progress in Brain Research. Elsevier, pp. 321-378. https://doi.org/10.1016/S0079-6123(05)51011-2

Mengod, G., Villaró, M.T., Landwehrmeyer, G.B., Martinez-Mir, M.I., Niznik, H.B., Sunahara, R.K., Seeman, P., O’Dowd, B.F., Probst, A., Palacios, J.M., 1992. Visualization of dopamine D1, D2 and D3 receptor mRNA's in human and rat brain. Neurochemistry International 20, 33-43. https://doi.org/10.1016/0197-0186(92)90208-9

Muller, L., Chavane, F., Reynolds, J., Sejnowski, T.J., 2018. Cortical travelling waves: mechanisms and computational principles. Nat Rev Neurosci 19, 255-268. https://doi.org/10.1038/nrn.2018.20

Munoz, D., Pelisson, D., Guitton, D., 1991. Movement of neural activity on the superior colliculus motor map during gaze shifts. Science 251, 1358-1360. https://doi.org/10.1126/science.2003221

Nicholson, A.A., Friston, K.J., Zeidman, P., Harricharan, S., McKinnon, M.C., Densmore, M., Neufeld, R.W.J., Théberge, J., Corrigan, F., Jetly, R., Spiegel, D., Lanius, R.A., 2017. Dynamic causal modeling in PTSD and its dissociative subtype: Bottom-up versus top-down processing within fear and emotion regulation circuitry: DCM in PTSD and Its Dissociative Subtype. Hum. Brain Mapp. 38, 5551-5561. https://doi.org/10.1002/hbm.23748

Pereira, D.B., Schmitz, Y., Mészáros, J., Merchant, P., Hu, G., Li, S., Henke, A., LizardiOrtiz, J.E., Karpowicz, R.J., Morgenstern, T.J., Sonders, M.S., Kanter, E., Rodriguez, P.C., Mosharov, E.V., Sames, D., Sulzer, D., 2016. Fluorescent false neurotransmitter reveals functionally silent dopamine vesicle clusters in the striatum. Nat Neurosci 19, 578-586. https://doi.org/10.1038/nn.4252

Pérez-Fernández, J., Kardamakis, A.A., Suzuki, D.G., Robertson, B., Grillner, S., 2017. Direct Dopaminergic Projections from the SNc Modulate Visuomotor Transformation in the Lamprey Tectum. Neuron 96, 910-924.e5. https://doi.org/10.1016/j.neuron.2017.09.051

Pérez-Fernández, J., Stephenson-Jones, M., Suryanarayana, S.M., Robertson, B., Grillner, S., 2014. Evolutionarily conserved organization of the dopaminergic system in lamprey: SNc/VTA afferent and efferent connectivity and D2 receptor expression: The Dopaminergic System in the Lamprey. J. Comp. Neurol. 522, 3775-3794. https://doi.org/10.1002/cne.23639 
828 Rabellino, D., Densmore, M., Frewen, P.A., Théberge, J., McKinnon, M.C., Lanius,

829

830

831

832

833

834

835

836

837

838

839

840

841

842

843

844

845

846

847

848

849

850

851

852

853

854

855

856

857

858

859

860

861

862

863

864 R.A., 2016. Aberrant Functional Connectivity of the Amygdala Complexes in PTSD during Conscious and Subconscious Processing of Trauma-Related Stimuli. PLOS ONE 11 , e0163097. https://doi.org/10.1371/journal.pone.0163097

Rice, M.E., Cragg, S.J., 2008. Dopamine spillover after quantal release: Rethinking dopamine transmission in the nigrostriatal pathway. Brain Research Reviews 58, 303-313. https://doi.org/10.1016/j.brainresrev.2008.02.004

Rice, M.E., Patel, J.C., Cragg, S.J., 2011. Dopamine release in the basal ganglia. Neuroscience 198,

112-137. https://doi.org/10.1016/j.neuroscience.2011.08.066

Robertson, S.D., Plummer, N.W., de Marchena, J., Jensen, P., 2013. Developmental origins of central norepinephrine neuron diversity. Nat Neurosci 16, 10161023. https://doi.org/10.1038/nn.3458

Shang, C., Liu, Z., Chen, Z., Shi, Y., Wang, Q., Liu, S., Li, D., Cao, P., 2015. A parvalbumin-positive excitatory visual pathway to trigger fear responses in mice. Science 348, 1472-1477. https://doi.org/10.1126/science.aaa8694

Smith, A.N., Kabelik, D., 2017. The effects of dopamine receptor 1 and 2 agonists and antagonists on sexual and aggressive behaviors in male green anoles. PLoS ONE 12, e0172041. https://doi.org/10.1371/journal.pone.0172041

Sparks, D.L., 1986. Translation of sensory signals into commands for control of saccadic eye movements: role of primate superior colliculus. Physiol. Rev. 66, 118-171. https://doi.org/10.1152/physrev.1986.66.1.118

Sulzer, D., Cragg, S.J., Rice, M.E., 2016. Striatal dopamine neurotransmission: Regulation of release and uptake. Basal Ganglia 6, 123-148. https://doi.org/10.1016/j.baga.2016.02.001

Tardif, E., Delacuisine, B., Probst, A., Clarke, S., 2005. Intrinsic connectivity of human superior colliculus. Exp Brain Res 166, 316-324. https://doi.org/10.1007/s00221-005-2373-z

Tu, G., Ying, L., Ye, L., Zhao, J., Liu, N., Li, J., Liu, Y., Zhu, M., Wu, Y., Xiao, B., Guo, H., Guo, F., Wang, H., Zhang, Lin, Zhang, Lu, 2019. Dopamine D1 and D2 Receptors Differentially Regulate Rac1 and Cdc42 Signaling in the Nucleus Accumbens to Modulate Behavioral and Structural Plasticity After Repeated Methamphetamine Treatment. Biological Psychiatry 86, 820-835. https://doi.org/10.1016/j.biopsych.2019.03.966

Verharen, J.P.H., Adan, R.A.H., Vanderschuren, L.J.M.J., 2019. Differential contributions of striatal dopamine D1 and D2 receptors to component 
processes of value-based decision making. Neuropsychopharmacol. 44, 2195-2204. https://doi.org/10.1038/s41386-019-0454-0

Villalobos, C.A., Wu, Q., Lee, P.H., May, P.J., Basso, M.A., 2018. Parvalbumin and GABA Microcircuits in the Mouse Superior Colliculus. Front. Neural Circuits 12, 35. https://doi.org/10.3389/fncir.2018.00035

Vokoun, C.R., Jackson, M.B., Basso, M.A., 2010. Intralaminar and Interlaminar Activity within the Rodent Superior Colliculus Visualized with Voltage Imaging. Journal of Neuroscience 30, 10667-10682. https://doi.org/10.1523/JNEUROSCI.1387-10.2010

Wei, P., Liu, N., Zhang, Z., Liu, X., Tang, Y., He, X., Wu, B., Zhou, Z., Liu, Y., Li, J., Zhang, Y., Zhou, X., Xu, L., Chen, L., Bi, G., Hu, X., Xu, F., Wang, L., 2015. Processing of visually evoked innate fear by a non-canonical thalamic pathway. Nat Commun 6, 6756. https://doi.org/10.1038/ncomms7756

White, B.J., Itti, L., Munoz, D.P., 2019. Superior colliculus encodes visual saliency during smooth pursuit eye movements. Eur J Neurosci ejn.14432. https://doi.org/10.1111/ejn.14432

Yilmaz, M., Meister, M., 2013. Rapid Innate Defensive Responses of Mice to Looming Visual Stimuli. Current Biology 23, 2011-2015. https://doi.org/10.1016/j.cub.2013.08.015

Zhou, Z., Liu, X., Chen, S., Zhang, Z., Liu, Y., Montardy, Q., Tang, Y., Wei, P., Liu, N., Li, L., Song, R., Lai, J., He, X., Chen, C., Bi, G., Feng, G., Xu, F., Wang, L., 2019. A VTA GABAergic Neural Circuit Mediates Visually Evoked Innate Defensive Responses. Neuron 103,

473-488.e6. https://doi.org/10.1016/j.neuron.2019.05.027

Zingg, B., Chou, X., Zhang, Z., Mesik, L., Liang, F., Tao, H.W., Zhang, L.I., 2017. AAVMediated Anterograde Transsynaptic Tagging: Mapping Corticocollicular Input-Defined Neural Pathways for Defense Behaviors. Neuron 93, 33-47. https://doi.org/10.1016/j.neuron.2016.11.045 
Figure 1

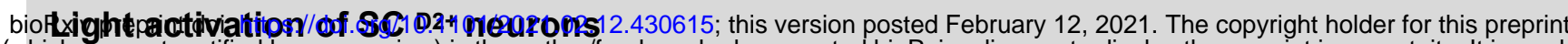
(which was not certified by peer review) is the author/funder, who has granted bioRxiv a license to display the preprint in perpetuity. It is made

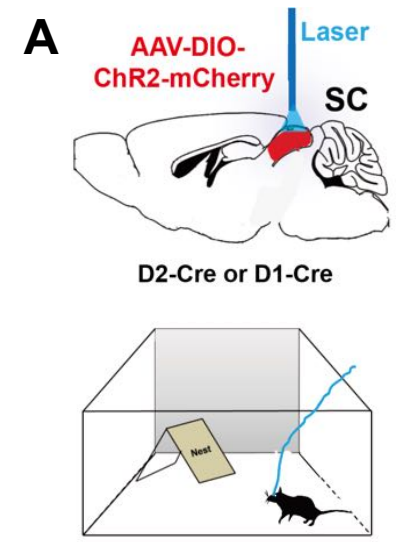

3 min habituation $>5$ min post stim

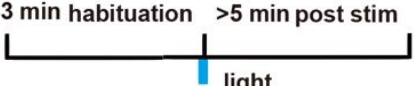

$\mathbf{E}$

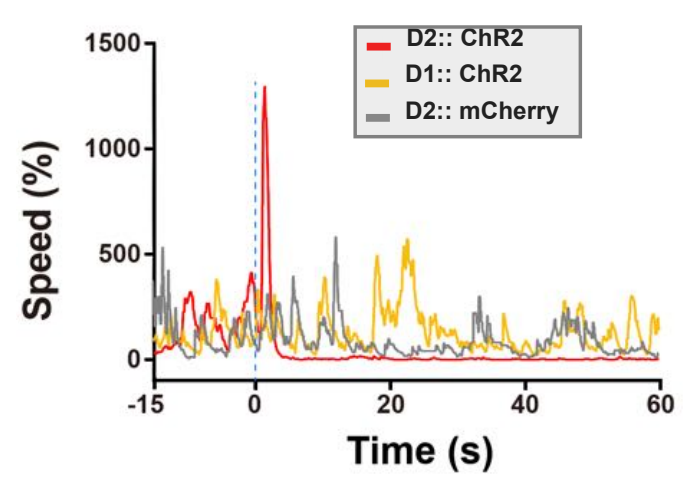

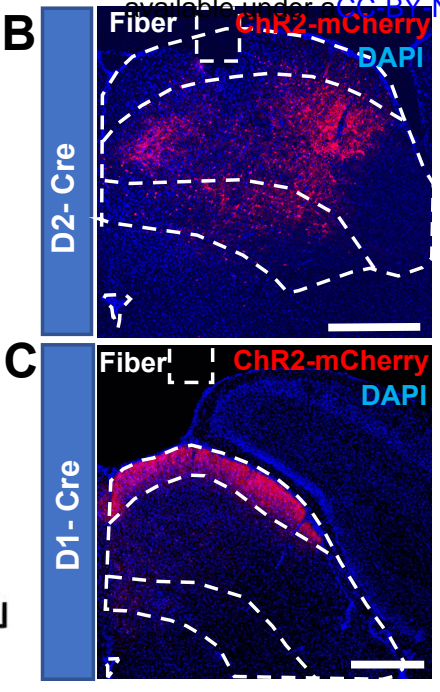

$\mathbf{F}$

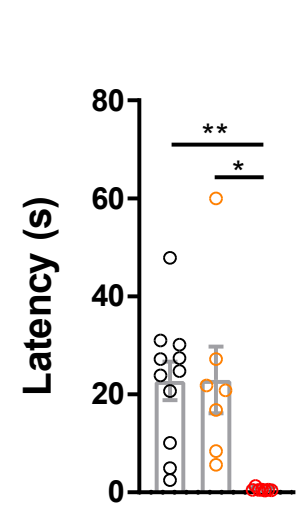

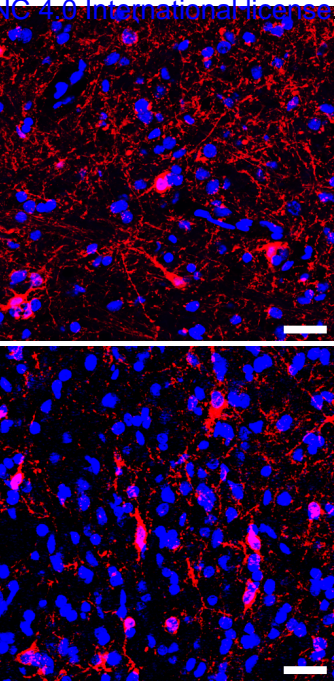
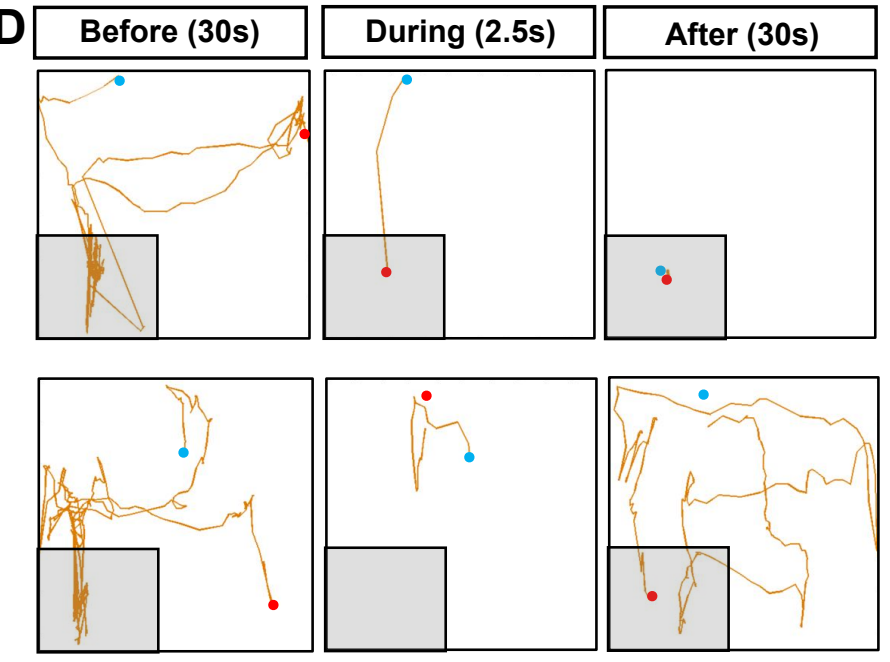

- Start Stop

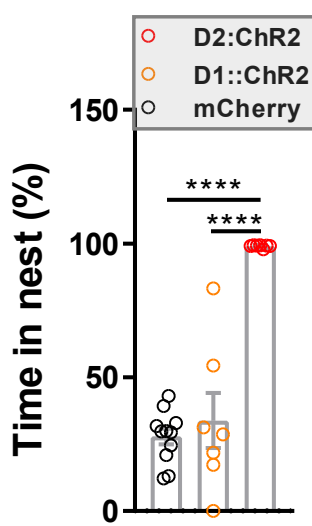

G

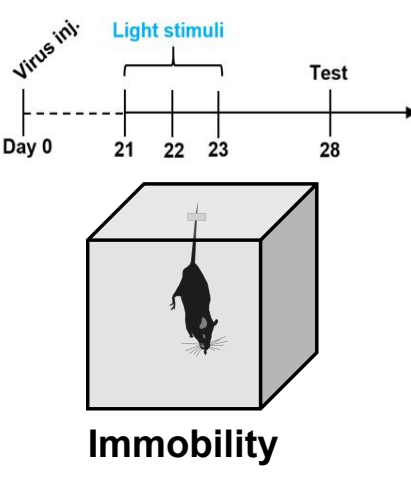

H

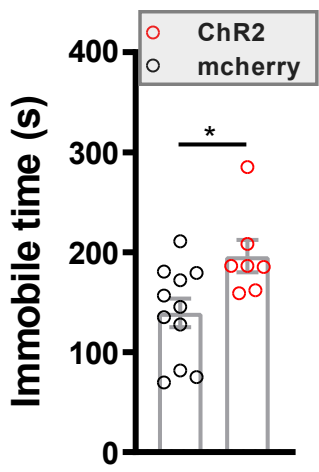

Light activation of SC ${ }^{\mathrm{D} 2+}$ neurons paired with tone
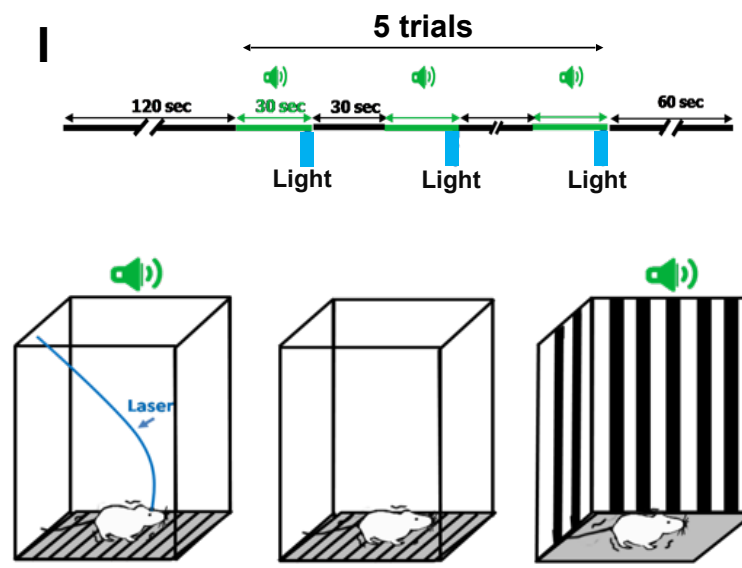

J

$\rightarrow$ ChR2-mcherry $(n=7)$
$\rightarrow \quad$ mCherry $(n=11)$

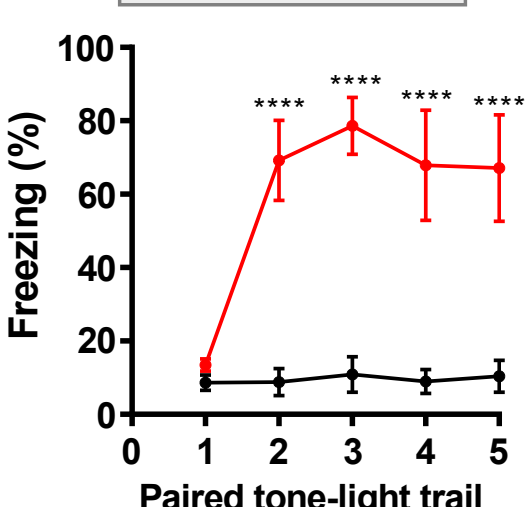

K

Context

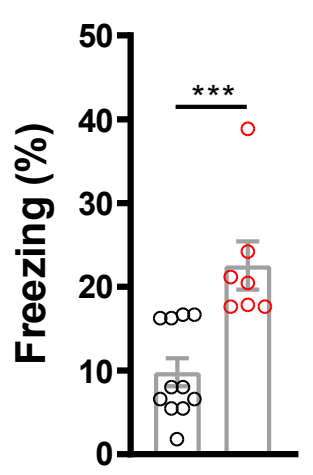

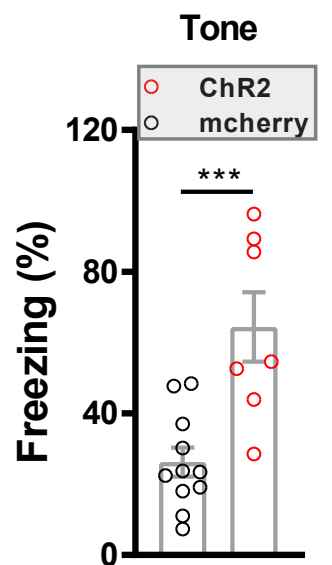




\section{Figure 2}

A bioRxiv preprint doi: htps://doi.org/10.1101/2021.02.12.430615; this version posted February 12, 2021. The copyright holder for this preprint (which was not certified by peer review) is the author/funder, who has granted bioRxiv a license to display the preprint in perpetuity. It is made Av-DiO-Hm4Di-mcherry

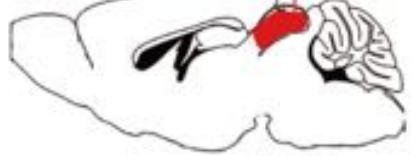

D2-Cre SC:: HM4Di

AAV-DIO-HM4Di-mCherry

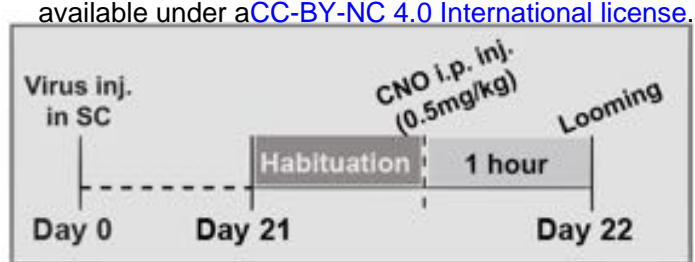

B
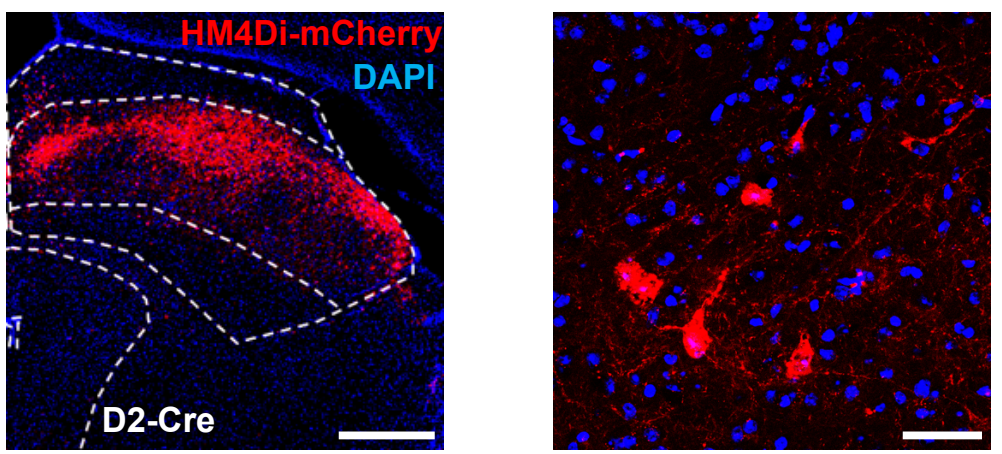

C

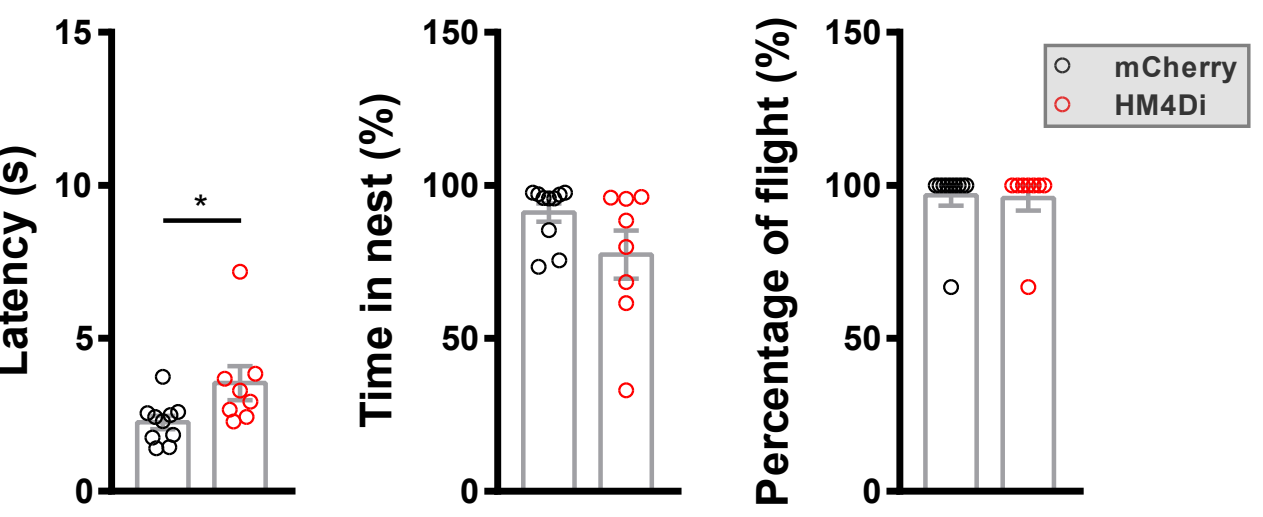




\section{Figure 3}

\section{D2 Agonist in SC}

bioRxiv preprint doi: https://doi.org/10.1101/2021.02.12.430615; this version posted February 12, 2021. The copyright holder for this preprint (which was not certified by peer review) is the author/funder, who has granted bioRxiv a license to display the preprint in perpetuity. It is made

A
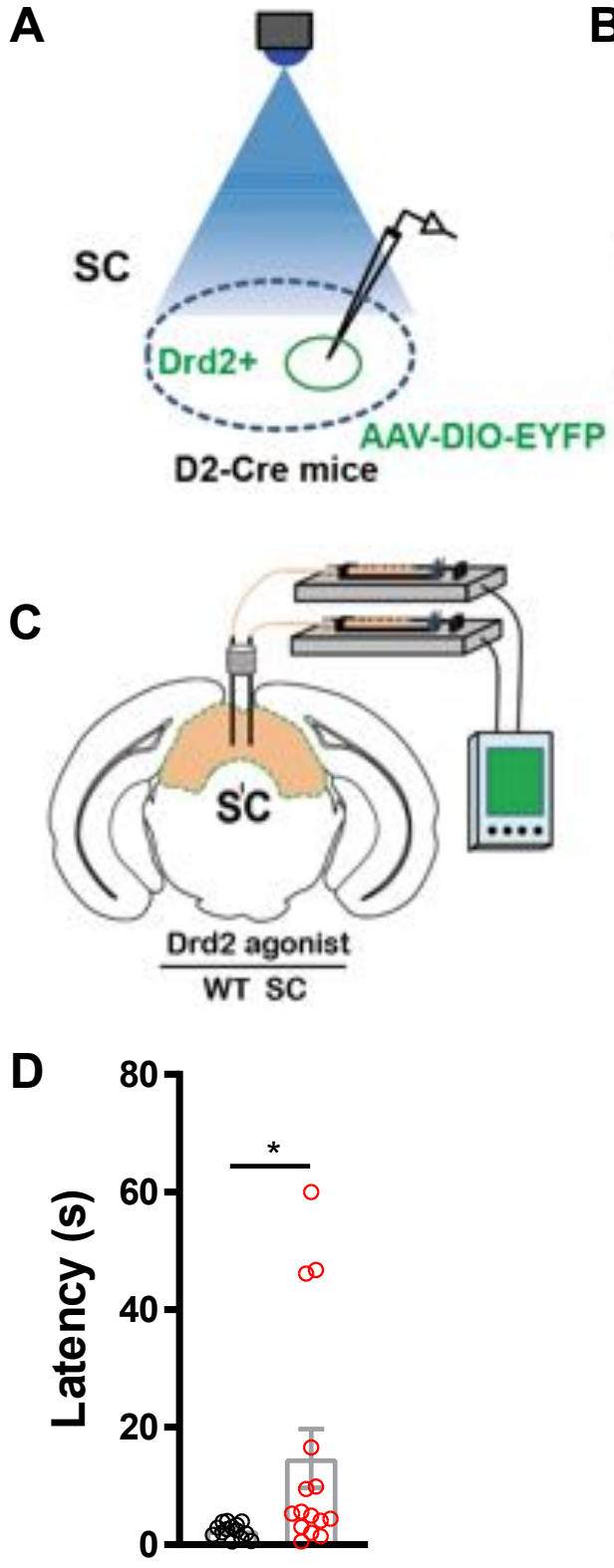

B vailable under aCC-BY-NC 4.0 International license.

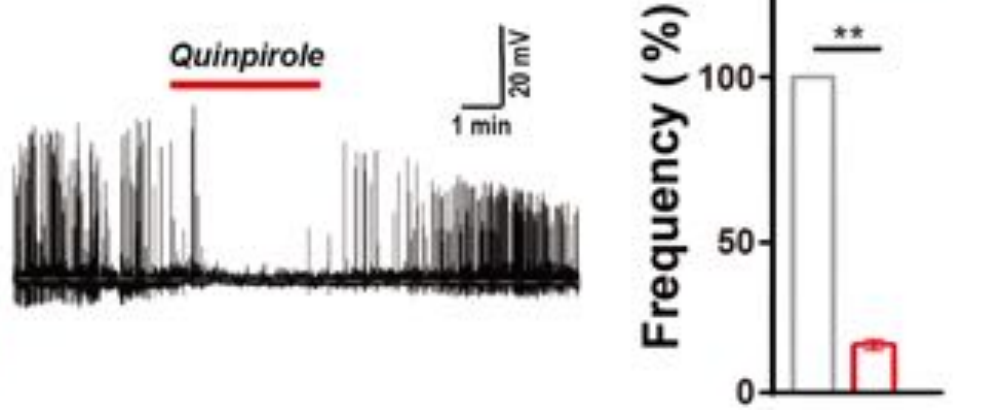

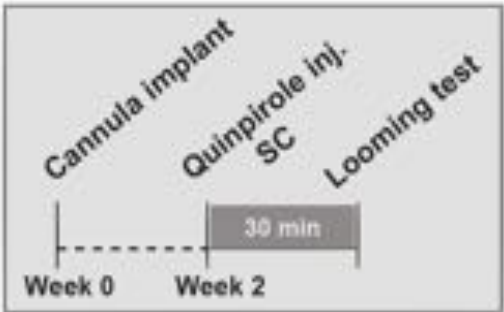
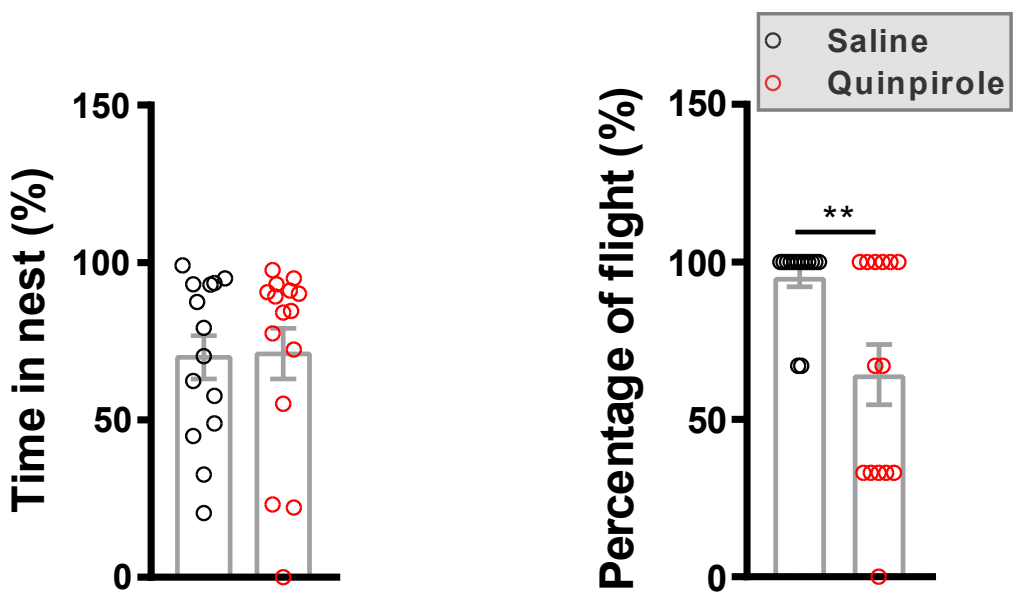


\section{Figure 4}

A

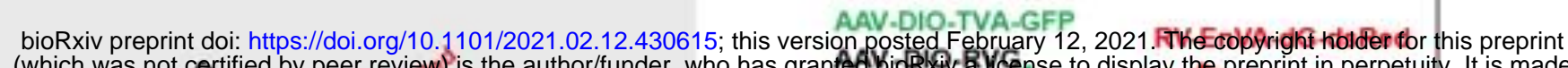
(which was not certified by peer review) is the author/funder, who has granfeakidf

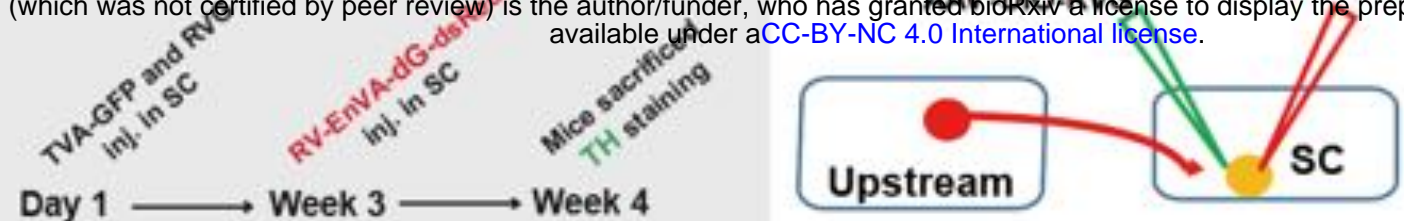

Day 1

Week 3

Week 4

\section{D2-Cre mice}

B

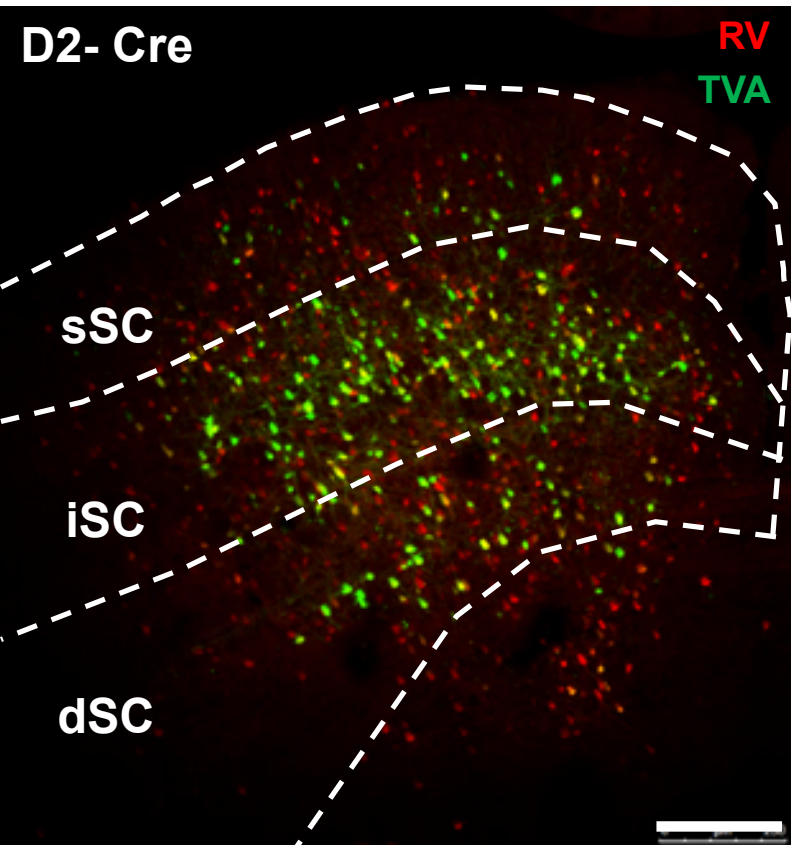

E
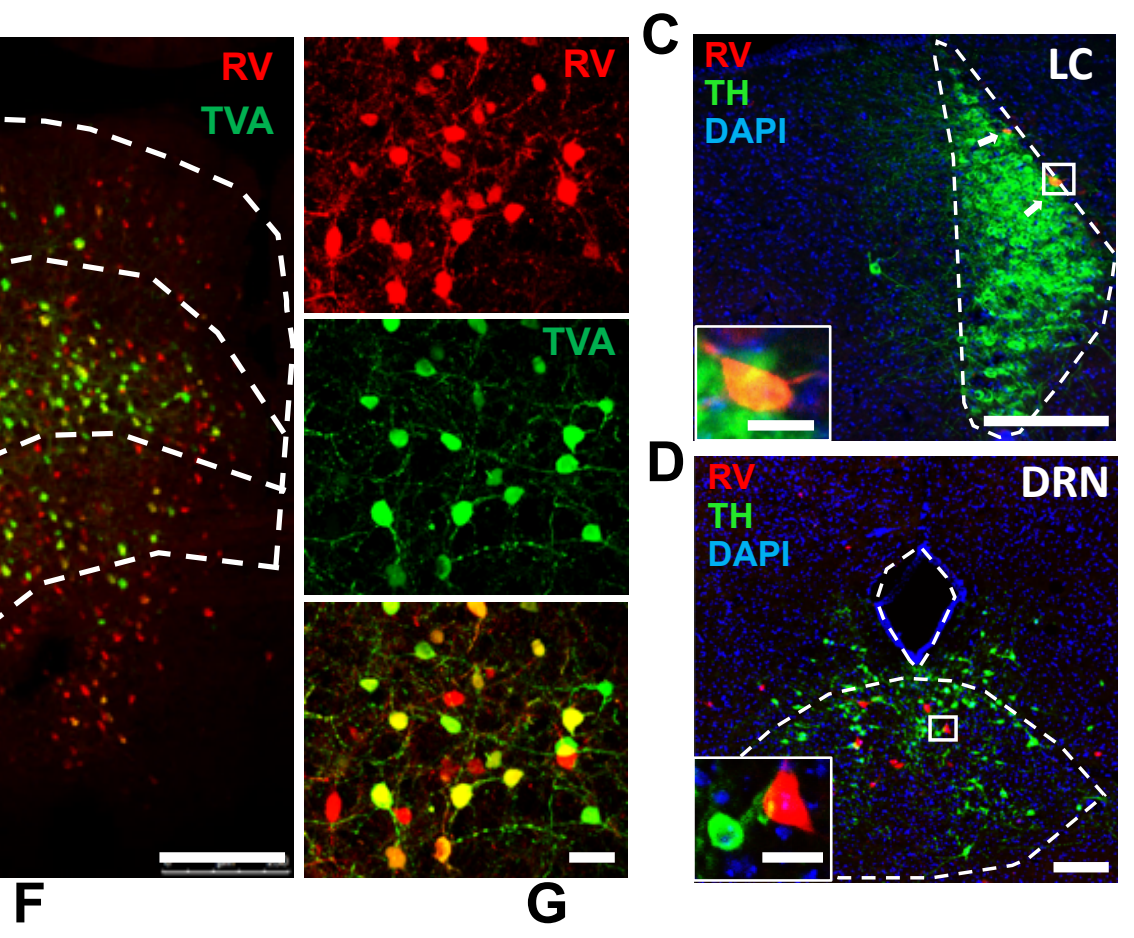

D

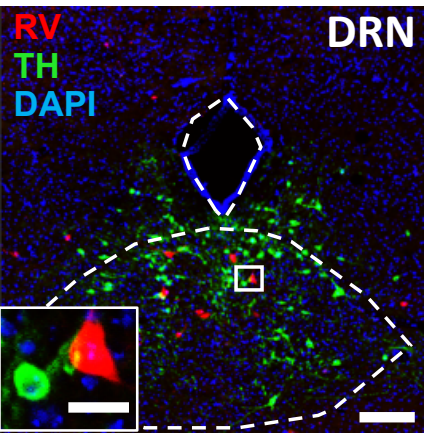

G

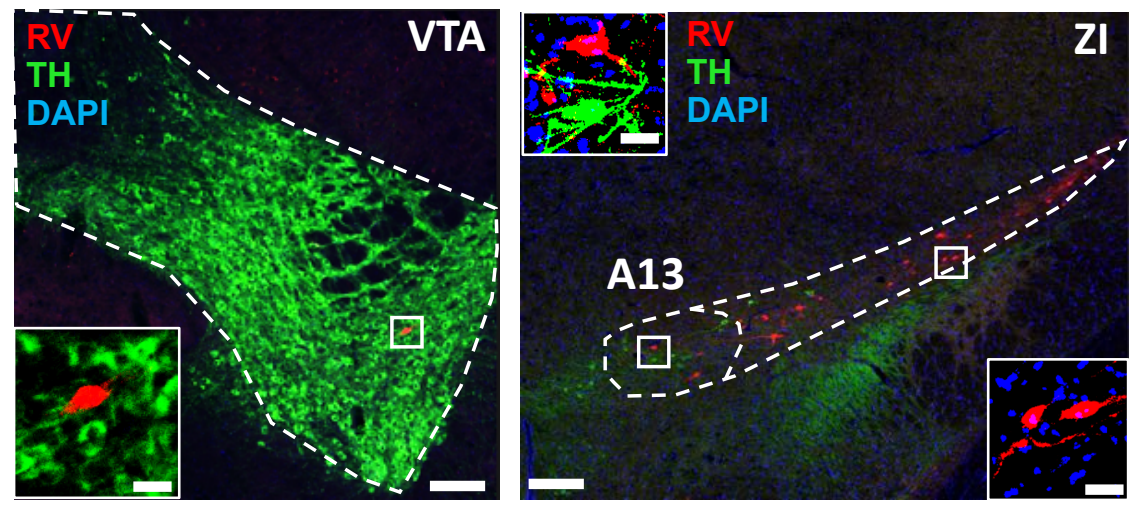

F
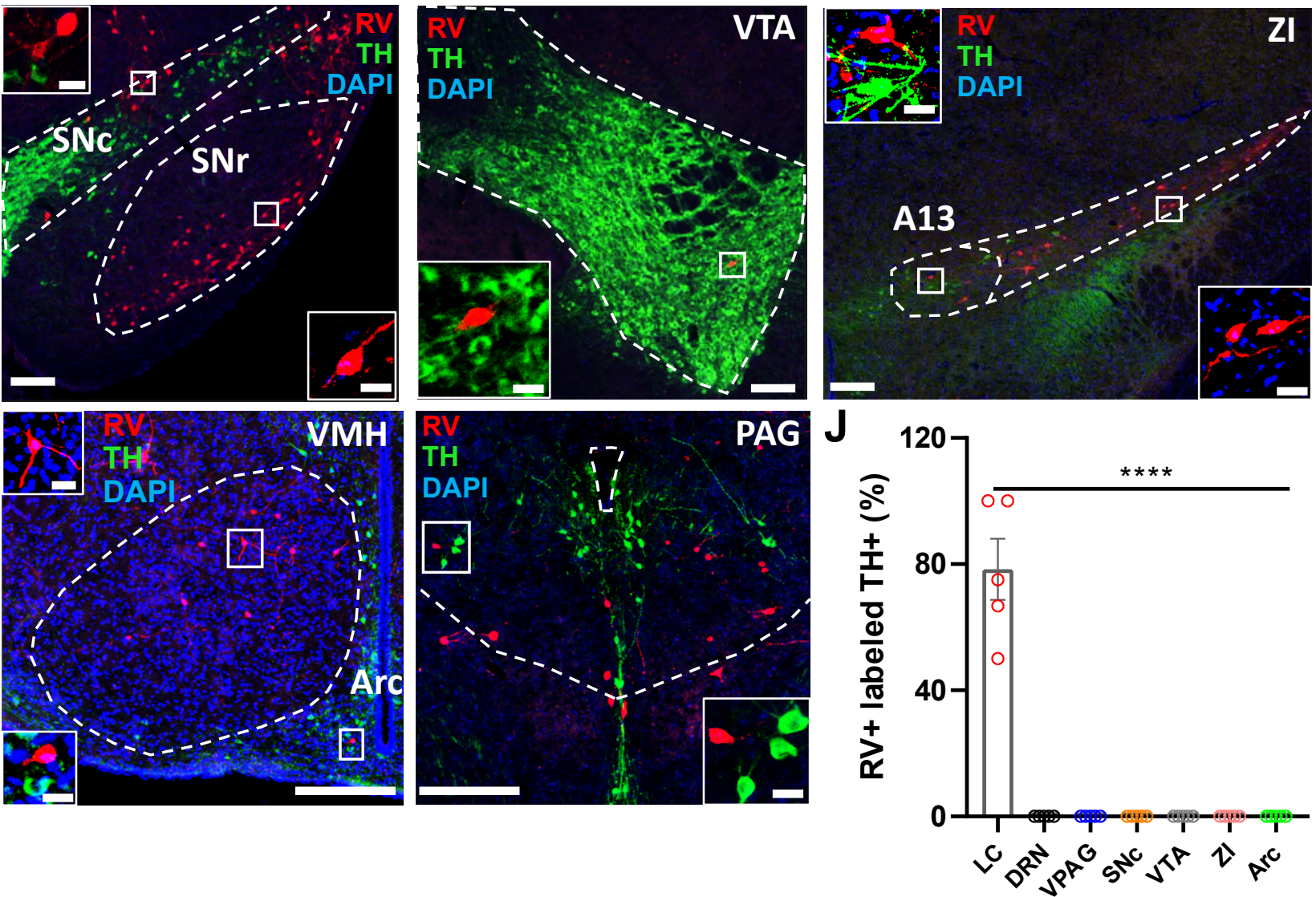


\section{Sup. Figure 1}

A

\section{PBG}

\section{Pn}
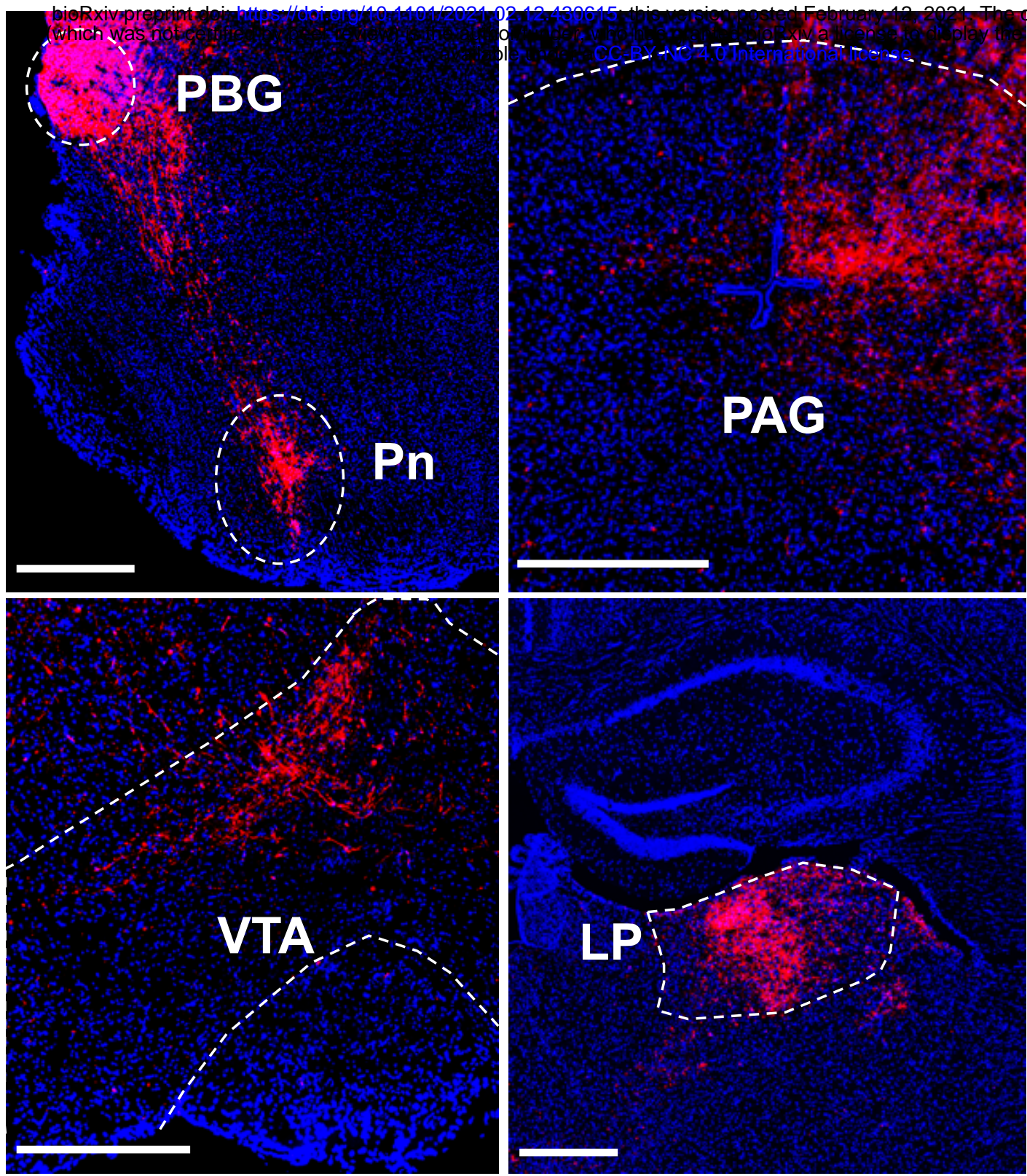

B

opyright holder for this preprin preprint in perpetuity. It is made

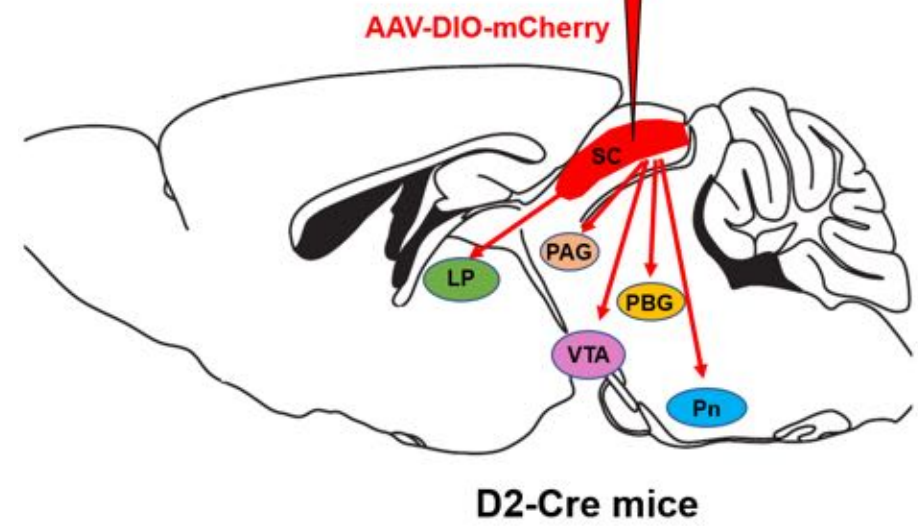

PAG: Periaqueductal gray

PBG: Parabigeminal nucleus

Pn: Pontine nuclei

VTA: Ventral tegmental area

LP: Lateral posterior thalamic nucleus

$\rightarrow$ : Output of SC D2 ${ }^{+}$cells 
Sup. Figure 2

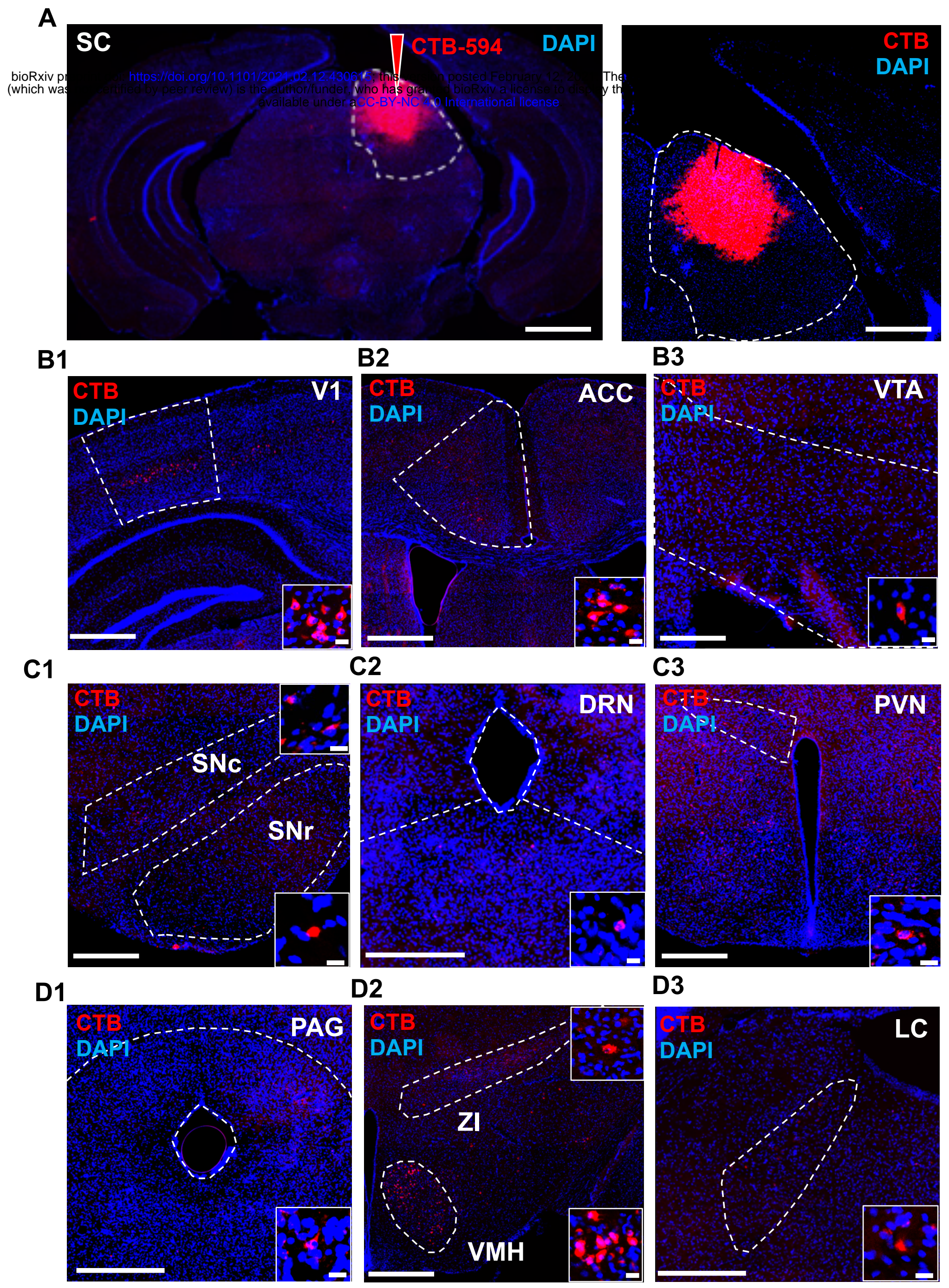


Sup. Figure 3

A

B
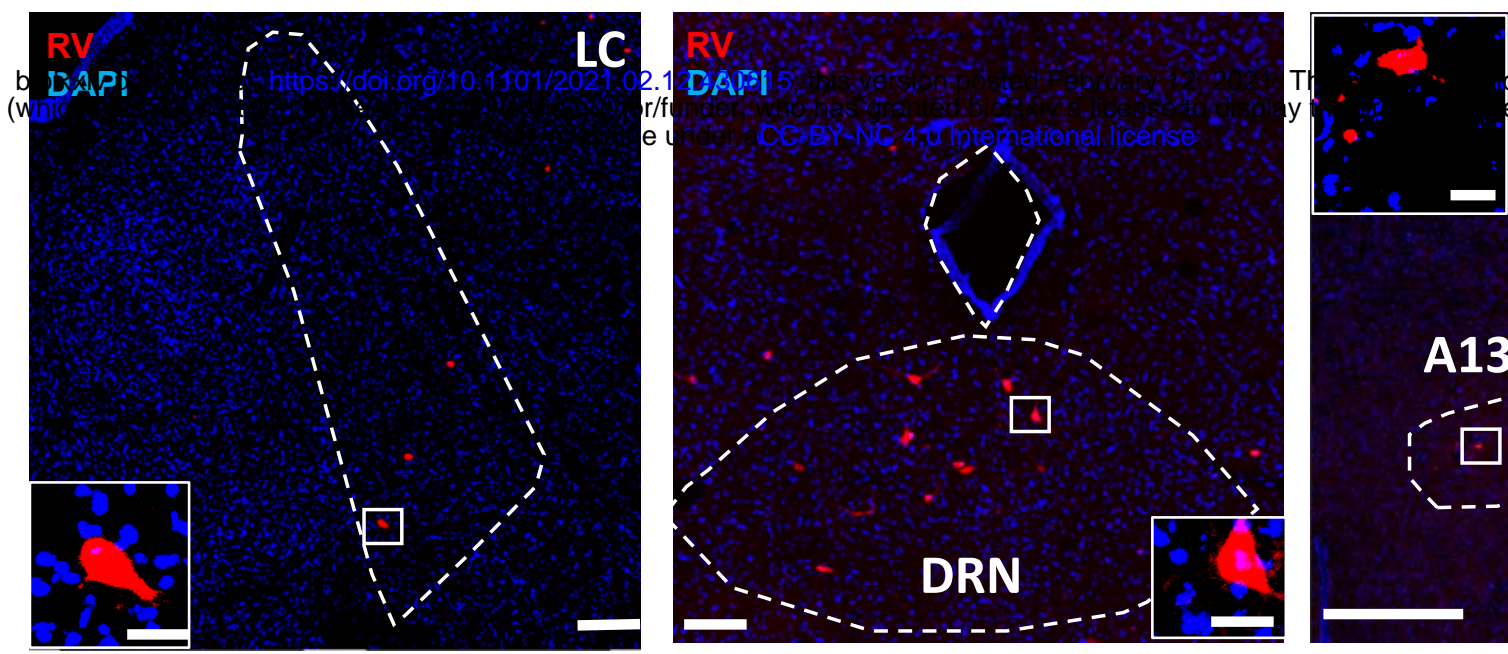

RV

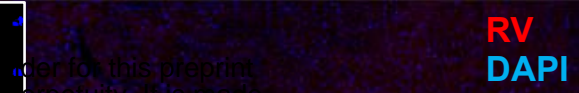

$-$

ZI
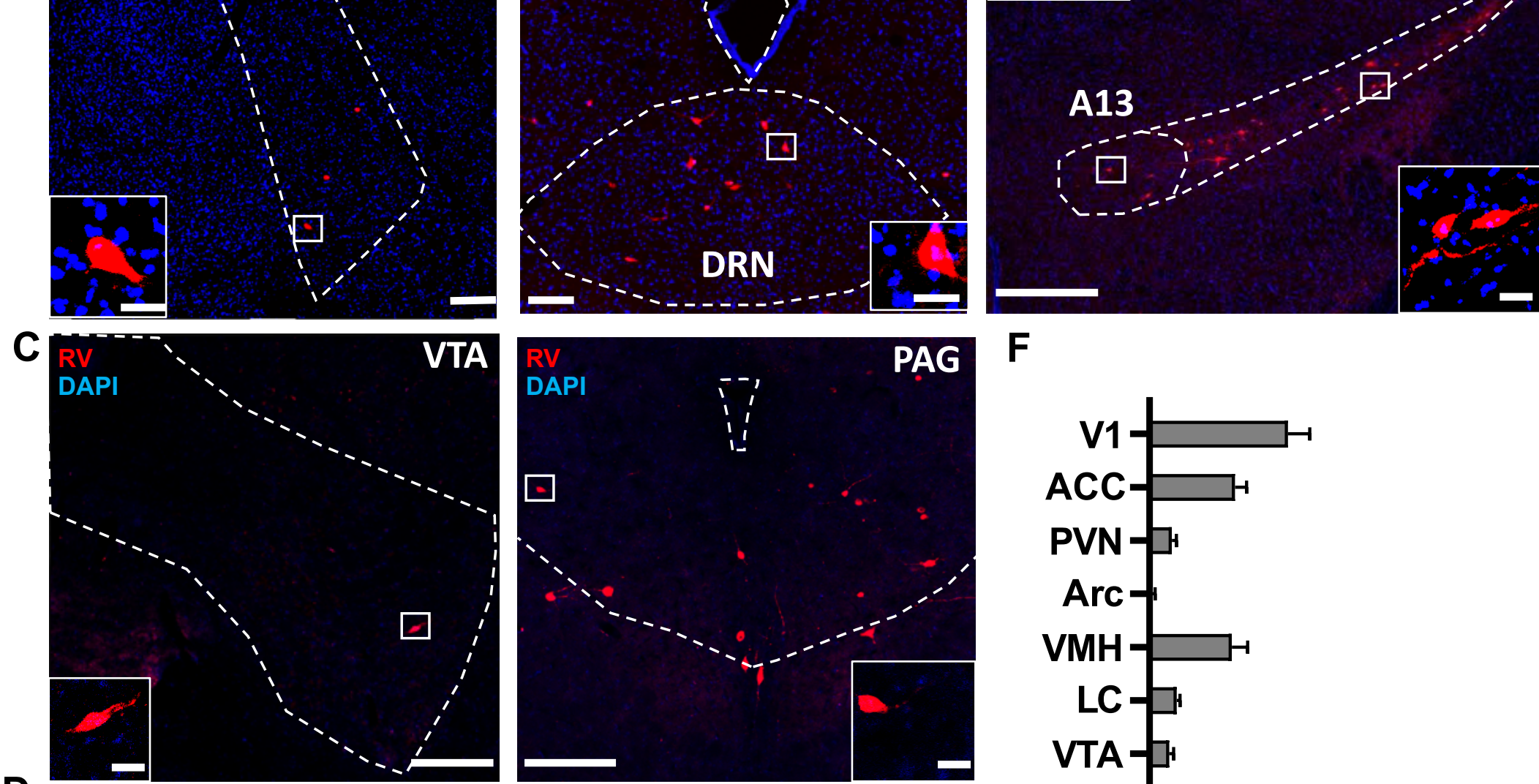

E

D

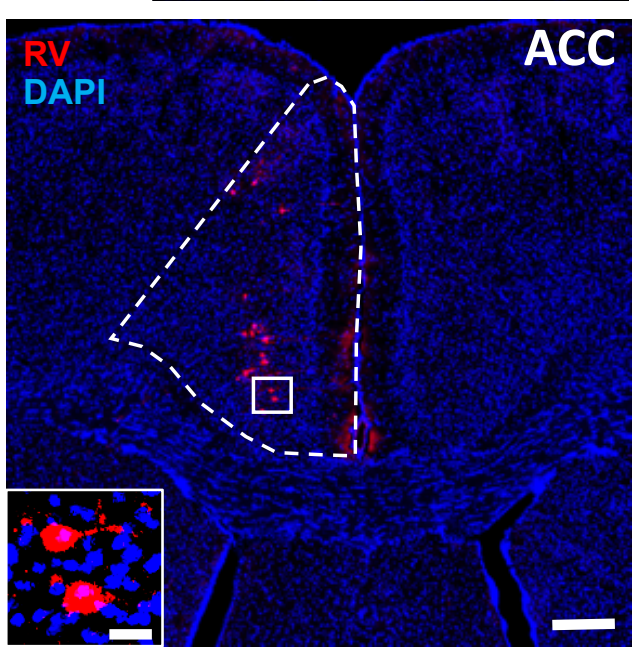

E

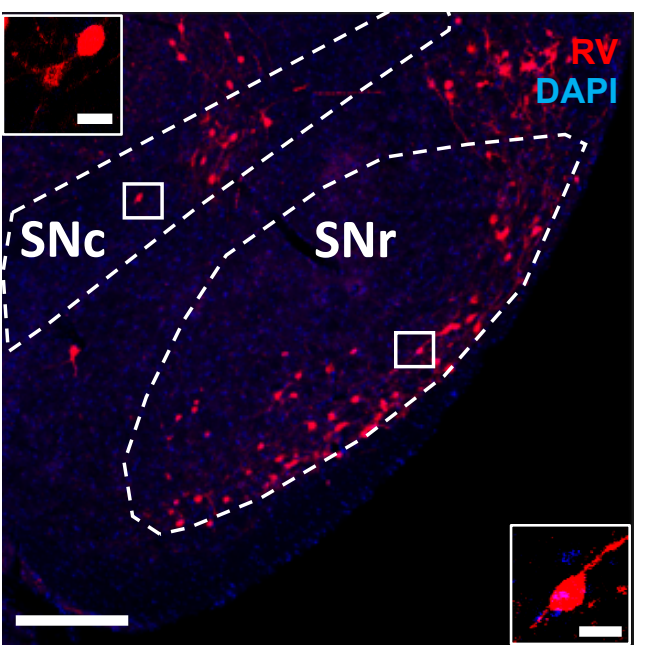

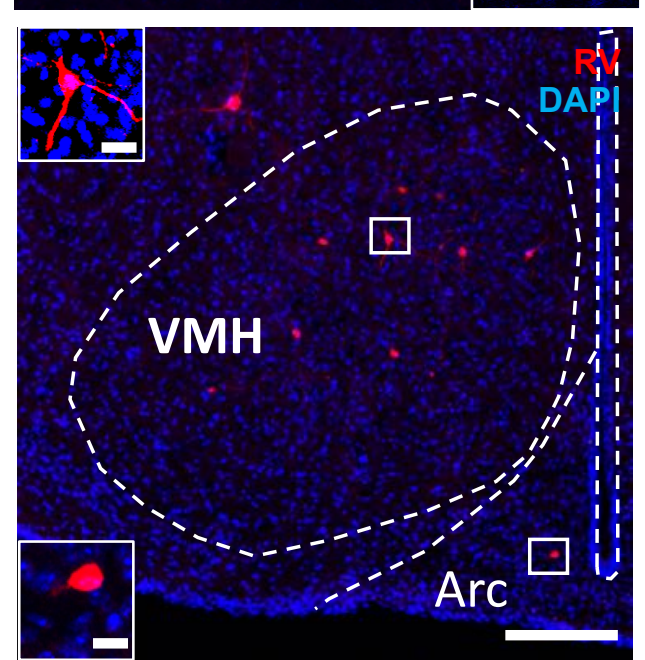

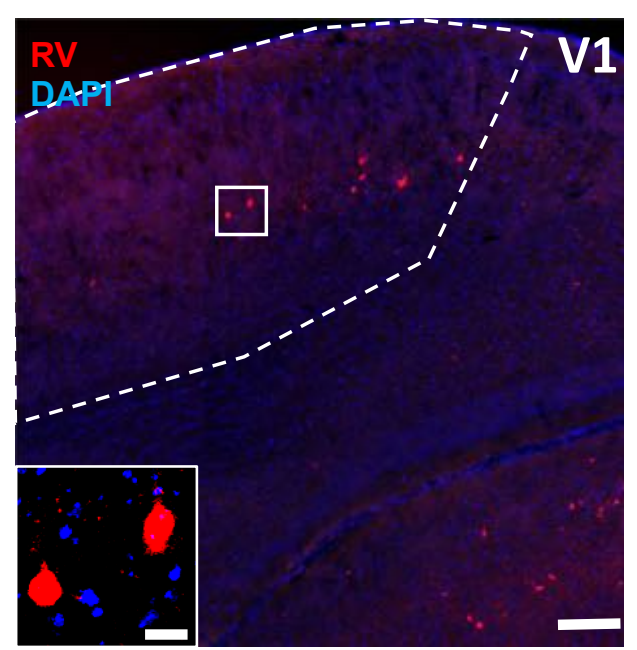

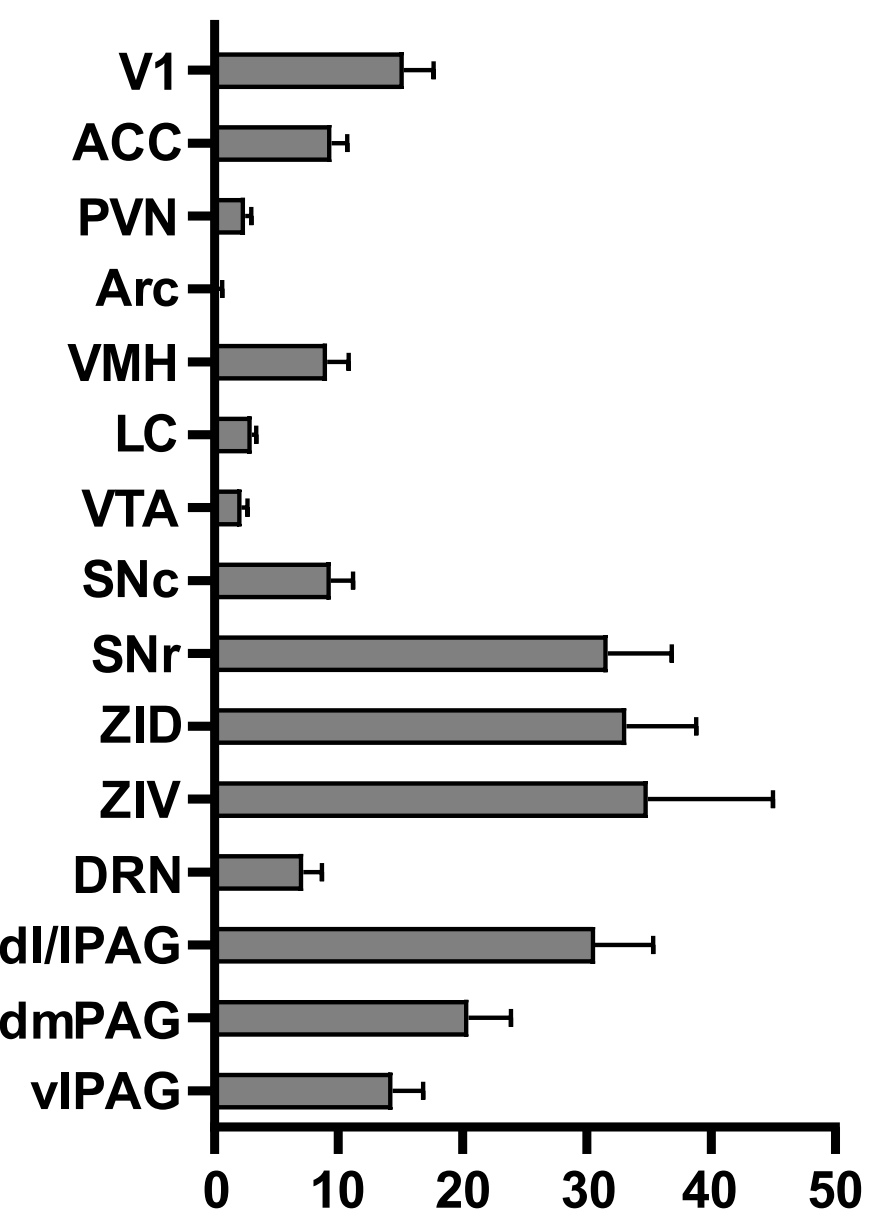

RV+/ Starter cells (\%) 